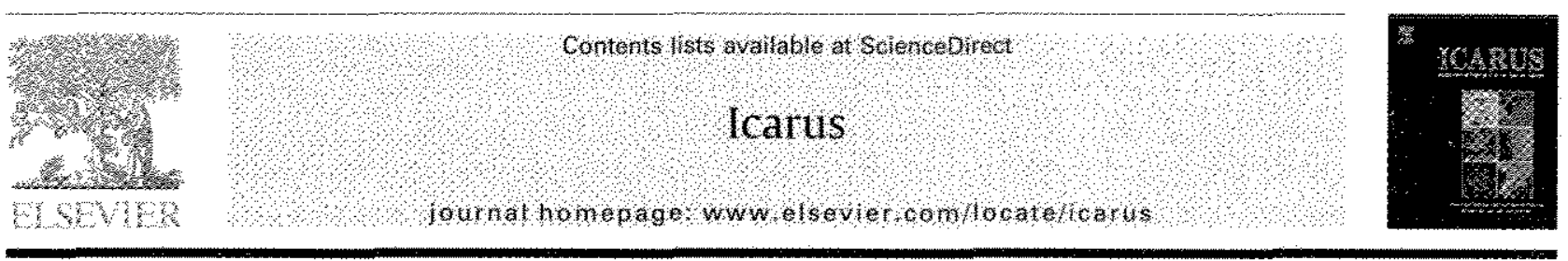

\title{
Observations of metallic species in Mercury's exosphere
}

\author{
Rosemary M. Killen ${ }^{a, *}$, Andrew E. Potter ${ }^{b}$, Ronald J. Vervack Jr. ${ }^{c}$, E. Todd Bradley ${ }^{d}$, William E. McClintock ${ }^{e}$, \\ Carrie M. Anderson ${ }^{\text {a }}$, Matthew H. Burger ${ }^{\text {a }}$ \\ "NASA Goddard Space Fight Center, Greenbett, MD 2077, United Srates \\ "National Opticl Astronomy Observatory. Tucsan, A2 85719 . Unifed States \\ "The Johns Hopkins Untiversity Applied Physics Laboratory, Laurel, MD 20723. United States \\ dDepartment of Physics, University of Cetitral Forida. Oriando, FI 32816, United States \\ "Laboratory for Atmospheric and Space Prysits, University of Colorado, Boulder, CO 80303 , Untited States
}

\section{A R TICLE I N FO}

\section{Article history:}

Received 27 October 2009

Revised 17 Feuruary 2010

Accepted 18 February 2010

Available online 15 March 2010

\section{Reywords:}

Mercury, Atmosphere

Mercury, Surface

\begin{abstract}
A B S T R A C T
From observations of the metallic species sodium ( $\mathrm{Na}$ ), potassium ( $\mathrm{K}$ ), and magnesium ( $\mathrm{Mg}$ ) in Mercury's exosphere, we derive implications for source and loss processes. All metallic species observed exhibit a distribution and/or line width characteristic of high to extreme temperature - tens of thousands of degrees $\mathrm{K}$. The temperatures of refractory species, including magnesium and calcium, indicate that the source process for the atoms observed in the tall and near-planet exosphere are consistent with ion sputtering andjor impact vaporization of a molecule with stusequent dissociation into the atomic form. The extended $\mathrm{Mg}$ tail is consistent with a surface abundance of $5-8 \% \mathrm{Mg}$ by number, if $30 \%$ of impact-vaporized Mg remains as MgO and half of the impact vapor condenses. Globally, ion sputtering is not a major source of Mg, but locally the spattered source can be larger than the impact vapor sotrce. We conclude that the $\mathrm{Na}$ and $\mathrm{K}$ in Mercury's exosphere can be derived from a regolith composition similar to that of Luna 16 soil (or Apollo 17 orange glass), in which the abundance by number is $0.0027(0.0028)$ for Na and $0.0006(0.0045)$ for. K.
\end{abstract}

Published by Stsevier Inc.

\section{Introduction}

We present observations of the metallic species sodium ( $\mathrm{Na}$ ), potassium ( $\mathrm{K}$ ), and magnesium (Mg) in Mercury's exosphere. Although sodium and potassium have been observed previously from ground-based platforms (eg., Potter et al., 2002), we present a map of the $\mathrm{Na} / \mathrm{K}$ abundance ratio over the observed sunlit disk of the planet. Magnesium was discovered in Mercury's exosphere during the second flyby of the innermost planet by the MErcury Surface, Space ENvironment. GEochemistry, and Ranging (MESSENGER) spacecraft (McCintock et al., 2009). Here, we present an analysis of the observed $\mathrm{Mg}$ column abundances and a discussion of the implications for source and loss processes. All metallic species observed exhibit a distribution and/or line width characteristic of high to extreme temperature. The temperatures of refractory species, including magnesium $(\mathrm{Mg})$ and calcium $(\mathrm{Ca})$, indicate that the source process for the atoms observed in the tail and near planet exosphere are consistent with ion sputtering and/ or impact vaporization of a molecule with subsequent dissociation into the atomic form. The very high energy metallic species may indicate that a resonance process of some kind is acting to produce

\footnotetext{
* Corresponding author.

Email adiress: Rosemary.Killenonasa.gov (R.M. Kinem).
}

a highly energetic gas that may not be thermal. We discuss the resuits in the context of assumed surface composition, and we assess the source and loss processes as constrained by the modeled magnetospheric configuration at the time of observation and other ancillary information.

\section{Observations}

We report in Section 2.1 observations of potassium and sodium in Mercury's exosphere taken at the McMath-Pietce solar telescope on Kitt Peak, Arizona, in support of the first MESSENGER llyby (M1) on January 14, 2008. In Section 2.2, we present observations of magnesium taken with the Ultraviolet and Visible Spectrometer (UVV) chamel of MESSENGER's Mercury Atmospheric and Surface Composition Spectrometer (MASCS) instrument during the spacecraft's second Mercury flyby (M2) on October 6, 2008 (Mcclintock et al, 2009). Although potascium has been observed previously fotter and Morgan. 1997; potter et al. 2002, and references therein), we present a map of the ratio of sodium to potassium in Mercury's exosphere. Physical data pertinent to the abservations or data reduction are listed in Table The high Doppler shift of Mercury with respect to the Sun is advantageous for these observations. 
Table 1

Mercury ephermerides for observations.

\begin{tabular}{|c|c|c|c|c|c|}
\hline Daté & Species & $R_{n}(A D)$ & $\begin{array}{l}\dot{R}, \text { heliocentric } \\
\text { radial velociny } \\
\text { (kmin } s^{-1)}\end{array}$ & $\begin{array}{l}\text { Phase } \\
\text { angle (o) }\end{array}$ & $\begin{array}{l}\text { Angtilat } \\
\text { diamete: } \\
\text { (arcsec) }\end{array}$ \\
\hline Jantaty 17,2008 & $\mathrm{Na}, \mathrm{K}$ & 0.336 & -8.72 & 63 & 6.2 \\
\hline October 6,2008 & Wo & 0,342 & -9.16 & 173 & NA \\
\hline
\end{tabular}

\subsection{Observations of the sodium and potassium exospheres}

Observations of the potassitm exosphere of Mercury were obtained at the McMath-Pierce solar telescope on January 17, 2008. three days after the first MESSENGER llyby. We observed the $\mathrm{K}$ $\mathrm{D}_{2}$ line at $766.49 \mathrm{~nm}$ at rest in air; the $K \mathrm{D}_{1}$ line is at $769.8974 \mathrm{~nm}$ in air. A large Doppler shift is advantageous for potassimm observations in order that the atomic line at rest with respect to the planet should coincide with the continum region of the solar flux and be removed from the telluric absorption lines as illustrated in Fig. 1. We used a $5^{\prime \prime} \times 5^{\prime \prime}$ image slicer (where " denotes arcsec) to direct the light from a $5^{\prime \prime} \times 5^{\prime \prime}$ square area on the planet to the entrance slit of the stellar spectrograph at the telescope. Because the angular diameter of Mercury as viewed from Earth was $6.17^{\prime \prime}$, three different observations covering a $5^{\prime \prime} \times 5^{\prime \prime}$ area were mosaicked together to produce a $5^{6} \times 10^{\prime}$ image covering the entire illuminated planet (Fig. 2). The phase angle of Mer cury as seen from Earth was $63^{\circ}$, and we were primarily observing the dawn side.

The K observations were reduced to column abundance using a $\mathrm{K}_{2} \mathrm{~g}$-value (photons $\mathrm{S}^{-1}$ atom ${ }^{-1}$ ) of 107.7 computed at a heliocentric radial distance $R_{\text {orb }}=0.336$ AU and a heliocentric radial velocity, $\dot{R}=-.8 .7 \mathrm{~km} \mathrm{~s}^{-1}(16: 00$ UTC), Note that the solar flux as seen at Mercury is shifted blueward (toward shorter wavelengths). but the emission in the exosphere is on the red side of the solat Fraunhofer feature as seen from Earth. The g-value (photons $s^{-1}$ atom $\left.{ }^{-1}\right)$ was computed using the solar flux atlas at the Kitt Peak National Observatory (KPNO) McMath-Mierce solar data archives (Kurucz et al., 1984) and an oscilator strength, $f$-value, of 0.682 for $\mathrm{K} \mathrm{D}_{2}$ from the National institute of Standards and Technology (NIST) atomic database (kalchenko et al., 2008). In spite of the large g-value and high solar continum, the line is still very weak. Pertinent observational data for the $K$ line are listed in Table 2. The heliocentric distance of Mercury, $R_{\text {om }}$ was obtained from the Jet Propulsion Laboratory (PL) Honizons website at the mean time of the observations. The photo-ionization lifetime of $k$ listed in Table 2 is from fulle et al. (2007); that for $\mathrm{Na}$ is derived from the theoretical cross section (Huebner et a1., 1992), both at
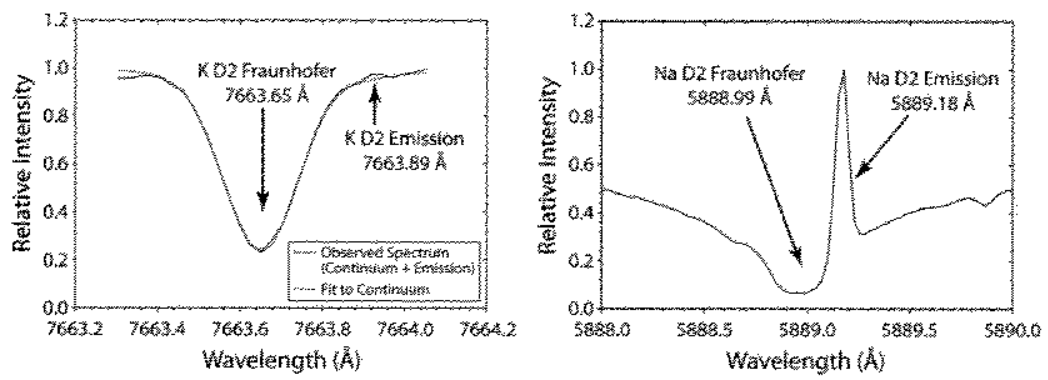

Fig. 1. A (left) The $\mathrm{K}_{2}$ emission feature (766.389 nm) is redshifted out of the solat fraunhofk line at 766 .365 nm Doppler-shifted wavetength. Extrattion of the line emission was performed fot each pixel in the three dimensional dataset $(x, y, \lambda)$ by subtraction of the continum shown by the red line, where $x$ and $y$ are ast $/$ west and north/south directions, tespectively, and $\alpha$ is wavelength. Because the $K$ line is weak, the pixels were binned by 2 in eact spatial dimension. $\mathrm{E}$ (right) The Na $\mathrm{D}$, line is simifarly redshifted, but the line is strong. Note that the Na Fratuhofer lines are broader than those of the Kines; thus, the Na emission is not shifted tompieing into the continum.

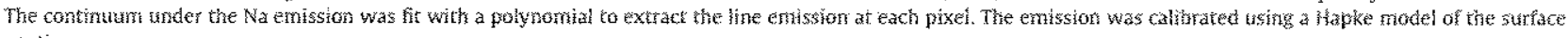
continian.

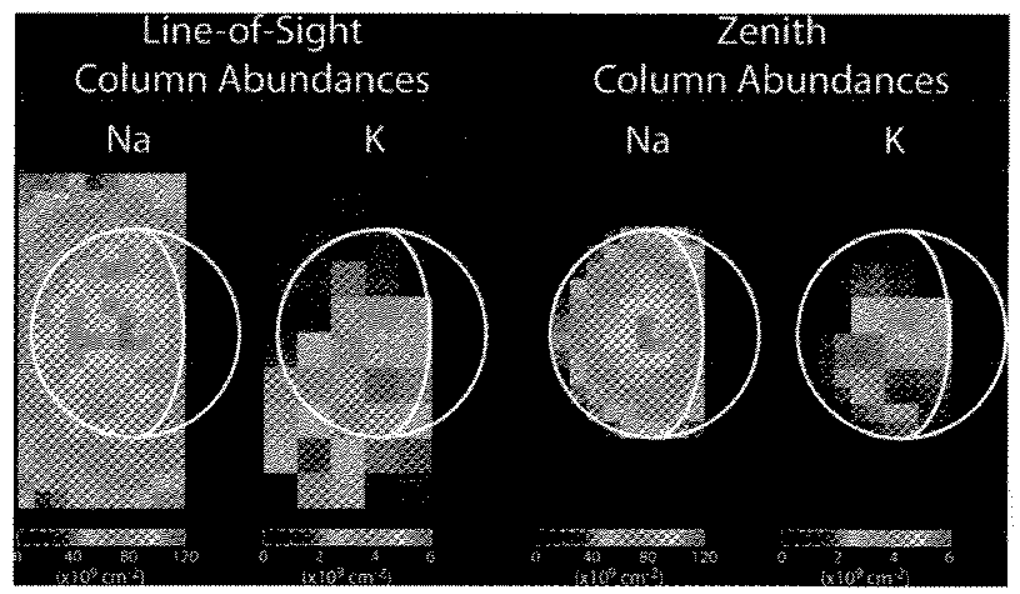

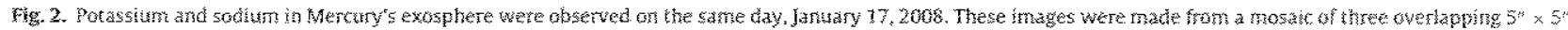

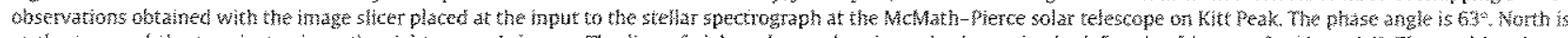

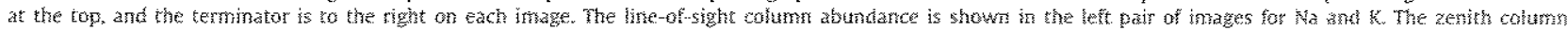

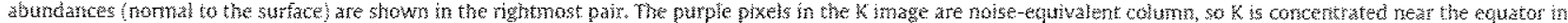
the northem hernsphere (orame pixels) and at high latitudes in the southern hernisphere (graen pixels). 
Tathe 2

Plysical data for the porassium and sodium observations.

\begin{tabular}{|c|c|}
\hline Parameter & Value \\
\hline Wavelettgth (mm) $\mathrm{I}^{2}\left(\mathrm{D}_{2}\right)($ rest $)$ & 76649 \\
\hline$g$-vatue $\mathrm{k}\left(\mathrm{O}_{2}\right)$ & 107.72 \\
\hline K photo forzation hetetine & $5.1 \times 10^{3} \leq(1.4 h)$ \\
\hline Wavelerigh $(\mathrm{mm}), \mathrm{Na}\left(\mathrm{D}_{2}\right)$ & 588.995 \\
\hline g-value Na $\left(\mathrm{O}_{z}\right)$ & 38.2 \\
\hline Na photo-ionization ufetme & $1.86 \times 20^{6} \mathrm{~s}(5.2 \mathrm{~h})$ \\
\hline Sub-solar yonzog & $182 \pm$ \\
\hline Stub-Earth longtude & $120^{\circ} \mathrm{E}$ \\
\hline Medin anomay & $301.5 \%$ \\
\hline
\end{tabular}

$R_{\text {orb }}=0.336 \mathrm{AU}$. Because the photo-ionization rates depend on the EUV flux, which depends on the solar cycle, we have used the rates calculated for 'quiet' Sun.

We obtained observations of the sodium $D$ lines with the McMath-Pierce solar telescope using the $5^{\prime \prime} \times 5^{\prime \prime}$ image slicer on each day during January $12-17,2008$, in support of the first MES. SENGER flyby. The $\mathrm{Na}_{2}$ line at $588.995 \mathrm{~mm}$ (at rest) was observed with the same instrument and identical setup as for potassium except for the wavelength setting. The data reduction process has been described in detail by killen et al. (2001), and the calibration procedure has been described by Killen et al. (1990). Because the image of Mercury was slightly larger than the field of view of the image slicer, mosaicked images of both sodium and potassium were made to determine the map of $\mathrm{Na} / \mathrm{K}$ emission above the sunIit disk of Mercury (Fig. 3). Note that the sodium D line emission is much more intense than the potassium D line emission, as illustrated in Fig. 1, primarily because the $\mathrm{K}$ abundance is much less than that of $\mathrm{Na}$, Both the background solar flux and the oscillator strength of the potassium D lines are strong. The signal to noise ( $\mathrm{S} / \mathrm{N}$ ) in the $\mathrm{Na} \mathrm{D}_{2}$ emission is 100 for the brightest pixel in the fig ure. The $S / N$ for the $K D_{2}$ emission line is 7 for the brightest pixel. Thus the noise-equivalent column is $10^{9} \mathrm{~cm}^{-2}$ for $\mathrm{Na}$ and $7 \times 10^{8}$ for $K$. All of our observed column abundances in $N a$ had $S / N$ values between 100 and 10 , and our $S / N$ values for $K$ were between 10 and 1.4. The $K$ abundance in the northem hemisphere is very low, especially at high latitudes.

Although the pixels in the $\mathrm{K}$ data shown in Fig. 2 were averaged over a $2 \times 2$ pixel region, the actual observed pixel elements were retained so that the division could be done. Potassium pixels in the fourth and fifth rows from the bottom (south) and columns 1-8 from left (west) were replaced by the averages of rows $2,3,6$, and 7 in their respective columns (i,e., the adjacent rows). Those pixels appeared to have data dropouts (see Fig. 2) but were off the planet except for the last two and would not contribute to the average $\mathrm{Na} / \mathrm{K}$ ratio. The line-of-sight $\mathrm{Na}$ /K ratio in the southern hemisphere $(\sim 36)$ is close to the smallest ratio found in the datasets considered by Potter et al. (2002), whereas the ratio in the northern hemisphere $(\sim 74)$ is near the mid-value found previously. Note that Potter et al. (2002) published only the average of the pixel ratios, although the ratios were computed in the same way as for Fig. $3 \mathrm{~A}$. The large $\mathrm{Na} / \mathrm{K}$ ratio in the northern hemisphere reflects the fact that most of the $K$ values in the northern hemisphere are noise-equivalent column. If we exclude from the average those pixels for which the $\mathrm{K}$ is at noise-equivalent column and ratio the zenith column abundances, the $\mathrm{Na} / \mathrm{K}$ ratio in the northern hemisphere is 49 and that in the southern hemisphere is 22. There is a small excess of $\mathrm{Na}$ in the northern hemisphere relative to the global average value and a large excess of $k$ in the southern hemisphere. The pixels outside of the illuminated disk

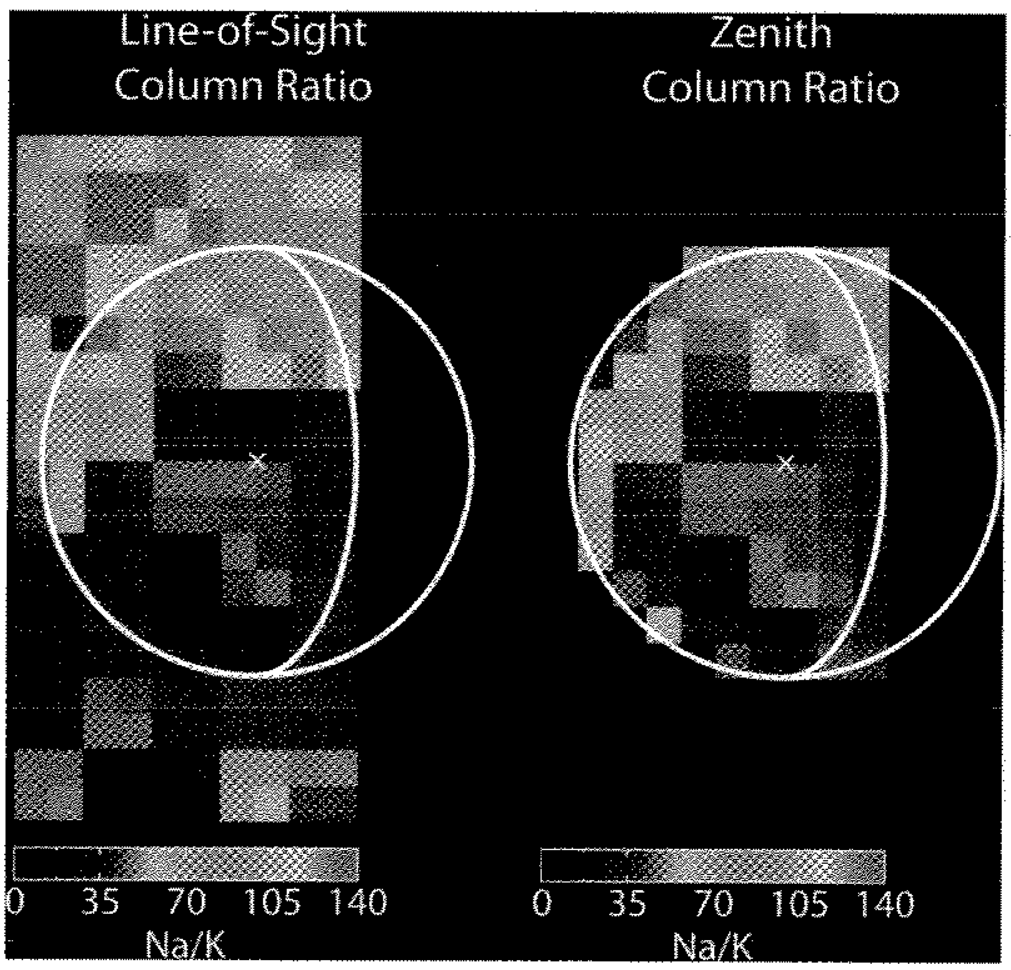

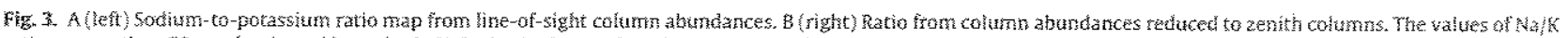

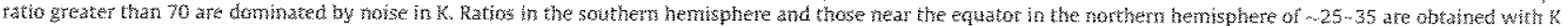

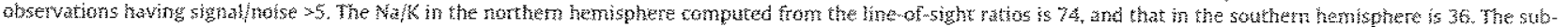
Earth point is maked with an $x$. North is at the top, and the teminator is to the fight. 
were not counted in the ratios because the $K$ line is weak and noise dominates the ratio off the disk in addition to noise, the difference in scale heights would affect the ratio off the disk.

Zenith column abundances, the integrated number density normal to the surface, were derived for each pixel from the line-ofsight column abundances at the same pixel using a Chamberlain exosphere and a temperature of $1500 \mathrm{~K}$ for both $\mathrm{Na}$ and $\mathrm{K}$ (Chamberiain and Hunten, 1987, chapter 7 ), under the assumption of a locally uniform exosphere. The derived average $\mathrm{Na}$ zenith column in the north, $4.4 \times 10^{10} \mathrm{~cm}^{-2}$, and that in the south, $3.3 \times 10^{10} \mathrm{~cm}^{-2}$, are within the range previously derived by Potter et al. (2002), taking into account that Potter et al. (2002) published line-of-sight abundances. The average did not include the central row (roughly equatorial) because there was an odd number of rows on the planet disk, but the addition of this row did not change the averages. The average $K$ zenith column in the north is $8 \times 10^{8}$ and that in the south is $13 \times 10^{8}$. The derived average $\mathrm{K}$ abundance in the north is very close to the noise-equivalent column $\left(7 \times 10^{8}\right)$, while that in the south is 1.9 times the noise-equivalent column. The average $N a$ abundance in the south divided by the average $K$ abundance in the south is 22 , excluding pixels for which $\mathrm{K}$ is noise-equivalent column, and this is the same as the average of the $\mathrm{Na} / \mathrm{K}$ computed per pixel. The average of the ratios of $\mathrm{Na} / \mathrm{K}$ computed per pixel in the north is dominated by the values near the limb where the $\mathrm{K}$ column is the noise-equivalent column unless those pixels are excluded from the average. The Na spatial variation represents only a $10 \%$ excess in the north relative to the average value over the entire Earth-facing illuminated disk. The observed $\mathrm{K}$ that is above noise level is in the southern hemisphere or close to the equator in the northem hemisphere. This local varaation is different from the global variation seen in the datasets analyzed by Potter et al. (2002), who found that $\mathrm{K}$ and $\mathrm{Na}$ vary similarly (i.e., both north or south). We find that the Na excess is in the northern hemisphere and the $\mathrm{K}$ excess is in the southern hemisphere. The Na is more or less peaked at the subsolar point. However, the distribution of $K$ is different. In the northern hemisphere, $K$ is almost entirely confined to within $30^{\circ}$ of the equator and near the subsolar point, where the maximum column abundance is about $5.5 \times 10^{8} \mathrm{~cm}^{-2}$; whereas in the southern hemisphere, $K$ is most abundant at high latitudes, where the column abundance is about $4 \times 10^{9} \mathrm{~cm}^{-2}$. Because the Caloris basin was visible in the northern hemisphere above $25^{\circ}$ latitude at the time of the observations and the $K$ was weakest there, we conclude that the Caloris ba. sin was not an enhanced source of $k$ to the exosphere.

\subsection{Observations of magnesium}

Magnesium was observed in Mercury's exosphere by the MESSENGER MASCS instrument during the second Mercury flyby (M2) by its 285.3-nm emission line (McClintock et al, 2009). MAS CS is a scanning grating spectrometer, so that individual emission lines are observed sequentially (Mcclintock and Lankton, 2007). Herein we analyze observations taken during the "tail-sweep," "fantall," and terminator regions, respectively. as discussed in Mccintock et al. (2009). The tail-sweep geometry is illustrated in Fig 4. Because MASCS observed arross the nightside shadow, in the analysis we correct for the fact that, although there is gas in the shadow, it cannot emit there because the emission lines are due to resonant transitions excited by the absorption of solar radiation. This geometry is discussed in Appendix $A$. The tall-sweep observations were designed to sweep through a vertical distance bounded by 23 Mercury radi $\left(R_{M}\right)$ as the spacecraft ap proached Mercury, so the spacecraft rotation angle increased. monotonically from $\pm 5^{\circ}$ to $\pm 40^{\circ}$. The data analyzed in this paper are confined to \pm 4 of the equatorial plane in order to avoid issues involving observations at high pointing angles with respect to the

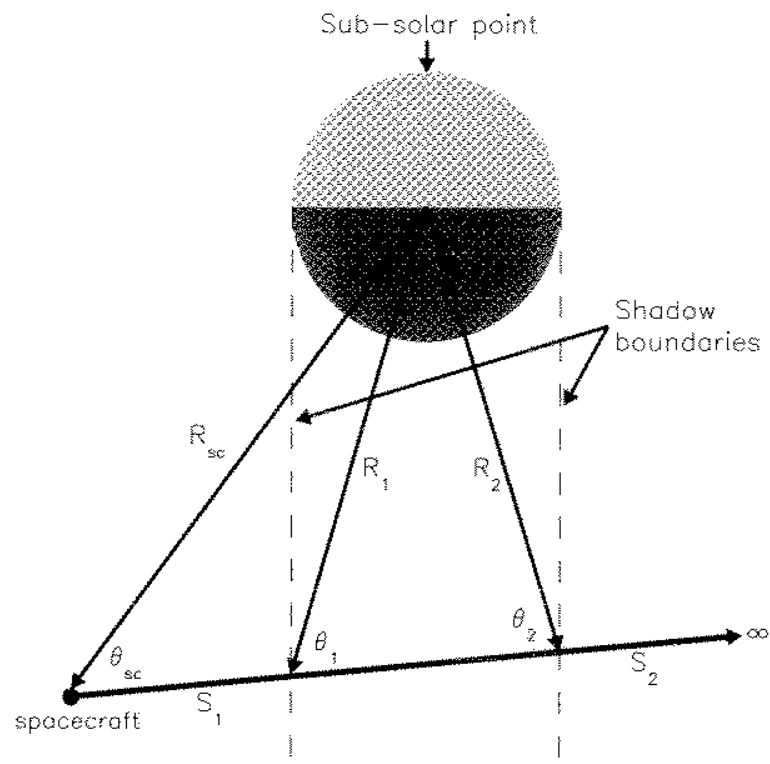

Fig. 4. Shadow geometry for the tail observations used in fitting the parameters for the Chamberlain exosphere. The spacecrat is at the position labeled "spacecraft," and the MASCs instrument looks across the tail at an angle $\partial_{\text {st }}$ with respect to the radial vector from the planet center to the spacecraft towatds infinity. The dashed lines delineate the shadow boundaries, and the distances $k_{1}$ and $k_{2}$ are the radis! distances from the planet center to the shadow botndary nearest and farthest from the spacecratt, respectively.

equatorial plane. In addition to the angle north/south with respect to the equatorial plane, we took into account the look angle with respect to the $y$-axis, which is in the equatorial plane perpendicular to the Sun-Mercury line, positive dawnward. These angles vary throughout the observational sequence. Observations in the tail region are illustrated in Fig. $5 \mathrm{~A}$, smoothed via interpolation between observed points using standard Interactive Data Language (DDL) routines. Because of the smoothing, the image in Fig. $5 \mathrm{~A}$ should not be used in a quantitative analysis but gives visual clues only. The physical data used in the data extraction and model are given in Table 3. The noise-equivalent column is $6 \times 10^{7} \mathrm{Mg}^{2}$ atoms $\mathrm{cm}^{-2}$ from the surface to $16,000 \mathrm{~km}$ behind the planet, and $4 \times 10^{7}$ from $16,000 \mathrm{~km}$ to $40,000 \mathrm{~km}$ behind the planet, so $S / \mathrm{N}$ is $\sim 10$ in this re gion. The solar spectrum is shifted blueward due to Mercury's motion toward the 5 un, but the flux absorbed by an atom at rest with respect to the planet is on the red wing of the solar line. The g-value in Table 3 reflects this frequency shift (Killen et al. 2009).

A least-squares fit to the data was run on a series of Chamberlain exosphere models solved at each observation point for the second Mercury flyby observational geometry for a series of 10 values of surface density $\left(n_{6}\right)$ and 10 values of temperature to determine the minimum variance solution (see Appendix A). The tangent col umn observed by MASCS within 4 of the equatorial plane was fit to a Chamberiain exosphere (Chamberain and Hunten, 1987) at the observed angles with respect to the planetary normat, taking the shadow into account. We also included a possible dawn-dusk asymmetry multiplicative factor in the solution to account for a possible dawn-dusk asymmetry, but for magnesium this factor converged to unity. The full Chamberlain exosphere model was used in this analysis, even in the tail region, and is appropriate because, unlike sodium, Mg is not subject to rabiation pressure and has a very long lifetime against photo-ionization, $57.5 \mathrm{~h}$ (Table 3), The best solution for $n_{0}$ and $T$ is given where the least squares deviation from the solution for all data points is mimum. The magne sium data taken in the $M 2$ tail sequence (Fig. $5 \mathrm{~B}$, asterisks) 

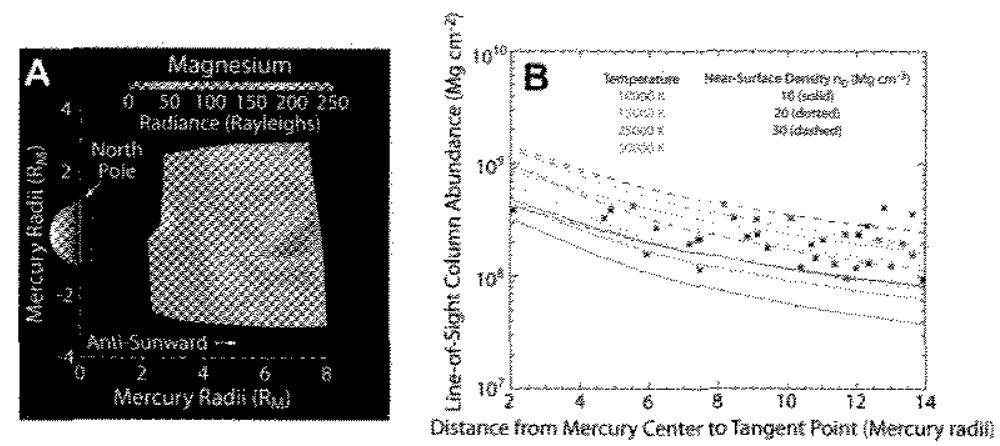

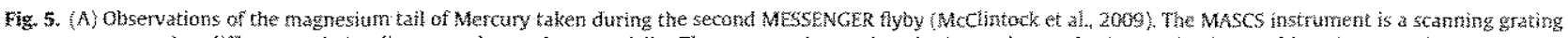
spectometer, so that different enission lines are observed secuentialy. The pattern observed in the image is merely the result of smoothing via interpolation between observed points using stondard int routines. The actual observet emission is peaked in the equatorial plane, but because the observarions were taken through the anti. sunward shadow, the observed emission includes only the illuminated portion of the exosphere outside the shadow. (B) A least-squares solution was fit to a matrix of Chambertain exospheres of different temperatures and near-surface densities. The models are for integrated emission across the tait, taking into account the lack of emission in the shadow. The best fit to the data, shown by asteriske, was for a temperature of $50,000 \mathrm{~K}$ and a density, hat of 16 cm ${ }^{3}$; however, this fit is probably influenced by the single observation at a radial distance $2 \mathrm{R}$, behind the planet. We allowed for the possibility of a different density on the dawn and duck sides, but the solution converged to the same number density, giving no dawn/dusk asymmetry. A number of models are shown for temperatutes of 10,000, 15,000, 25,000 and $50,000 \mathrm{~K}$, respectively, each for surface number densities of 10,20 , and $30 \mathrm{Mg}$ atoms $\mathrm{cm}{ }^{*}$. Note that we are seeing only the escaping component of the exosphere in this region. The models are such that a higher surface number density will compensate for a lower temperature source, but lower temperature solutions require higher emission near the ilanet than observed. More data points in this region would give greater confidence in the solution.

Table

Physical data for Mg.

\begin{tabular}{|c|c|}
\hline Patrameter & Value \\
\hline -vatue ar M2 for 265.296 nm line (vacurm) & $0.317 \%$ phtotons stam \\
\hline Shoto- ionzation wate ar Earty & $5.66 \times 10^{7 /} \mathrm{s}^{\prime}$ \\
\hline Dhoto-ionzation pate al Mercury.M2 & $4827 \times 10^{-6 i}$ \\
\hline Gnization ifetime at Mercury $\mathrm{M2}$ & $575 n$ \\
\hline
\end{tabular}

converged to a Chamberlain exosphere with a near-surface density $n_{0}=16 \mathrm{~cm}^{-3}$ and a temperature of $50,000 \mathrm{~K}$ (Fig. $5 \mathrm{~B}$ ). However, the solution is by no means unique as shown by the curves in Fig. $5 B$ for solutions with temperatures ranging from $10,000 \mathrm{~K}$ to $50,000 \mathrm{~K}$ and surface number densities of 10,20 and $30 \mathrm{~cm}^{-3}$, respectively. A low temperature can be compensated by a high density at the surface to fit the data in the tail region. The bestfit solution is forced by the single low data point at $2 R_{M}$. The presence of an extended $\mathrm{Mg}$ exosphere cannot be due to radiation pressure, and loss by photo-ionization is negligible.
We performed the same type of solution on the $\mathrm{Mg}$ "fantail" data obtained as the spacecraft rolled through $180^{\circ}$ from boresight pointing dawnward, through north, toward a duskward line of sight as the spacecraft moved toward the planet from approximately $2550 \mathrm{~km}$ to approximately $350 \mathrm{~km}$ behind the planet (Fig. 68). This geometry was taken into account in the analysis. The Mg fantail data ate illustrated by the asterisks in Fig. 6B, along with the least-squares solution shown by the solid red line, and models at temperatures of $25,000,40,000$, and $50,000 \mathrm{~K}$, respectively, at surface densities, $n_{0}$ of 5 and $9 \mathrm{~cm}^{-3}$. The lower set of lines are those run at $n_{0}=5 \mathrm{~cm}^{2}$, and the upper set of curves are those run at $n_{0}=9 \mathrm{~cm}^{-3}$

The solution for the fantail converges to a lower temperature. $25,000 \mathrm{~K}$, and a lower surface density, 9 , than the solution for the tail data, but the temperature is poorly constrained in either case. However, the temperature derived from the fantail data is still 20 times higher than that indicative of a photon-stimulated desorption (PSD) source, which would give $1200 \mathrm{~K}$ (Madey et al., 1998), and 5 times higher than that expected from a hypervelocity impact source, which would give about $5000 \mathrm{~K}$ or less (e.g. Berezhnoy and
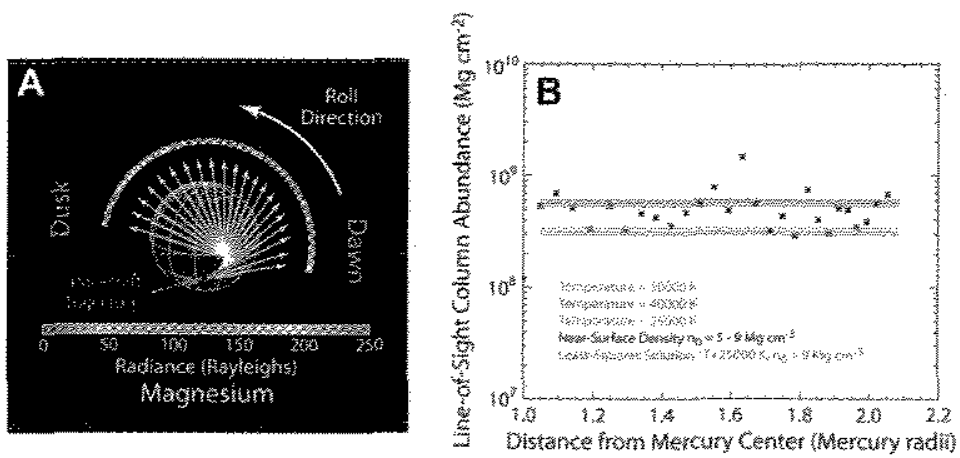

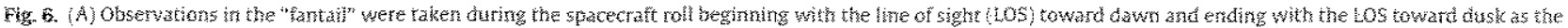

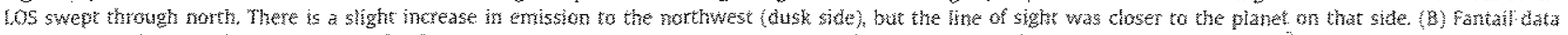
inustrated by the asterisks are plotted with a least-squares solution (fect). at a temperature of $25.000 \mathrm{k}$ and surace number dersity of $9 \mathrm{~cm}^{-3}$. other models are shown for

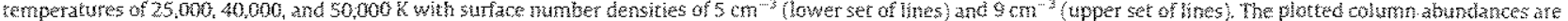
observed line-of-sight abundatces. This geometry does not constran temperatute as a result of the fact that the observations are in the near-tail ragion at a very linired range of distances from the planet. 
Kumov, 2008). The extreme temperature fit in the tail and fantail region is inconsistent with a PSD source for the $\mathrm{Mg}$ atoms reaching this region of the exosphere and probably requires a secondary process such as dissociation of a molecular source that was initially vaporized or sputtered from the surface, because the atoms are more energetic than they would be if derived from PSD, impact vaporization, or ion sputtering. This inference is consistent with that made from observations of $\mathrm{Ca}$ (Killen at al, 2005).

After the spacecraft completed the roll manewver, MASCS executed $\mathrm{Mg}$ observations in the near-terminator region while still on the nightside (McClintock et al., 2009, Fig. 2). For this dataset the boresight was looking at the nightside surface, but only that portion of the exosphere above the shadow was illuminated and therefore seen in emission. We modeled the emission between the spacecraft and shadow, taking into account the botesight angles with respect to the surface. A fit to the $\mathrm{Mg}$ data in the near-terminator region (Fig. 7B) was less successful than the fits to the tail and fantail data, probably because the exosphere is non-uniform in this region and the data cannot be made to fit a single model. In the terminator region the observed line-of-sighe column, that between the spacecraft and the shadow, sampled a restricted range of the exosphere. Each data point (asterisks) represents not only a different spacecraft distance but also a different distance behind the terminator. Fits are shown tor a temperature of $70,000 \mathrm{~K}$ (green) and a temperature of $10,000 \mathrm{~K}$ (red) with surface number densities of 50 (lower curves) and $100 \mathrm{~cm}^{-3}$ (upper curves). As the spacecraft approached the terminator, the data were fit by a progressively lower temperature and a higher surface number density. The data can be fit with a temperature of $10,000 \mathrm{~K}$ provided that the surface number density is above $50 \mathrm{~cm}^{-3}$, but the fits are non-unique. The first three points were not included in the fit because they represent a very short line of sight in sunlight.

\section{Data analysis}

\subsection{Surface composition}

The surface composition of Mercury is not known at present. Table 4 shows abundance of elements from linar solls that will be used to constrain possible surface compositions at Mercury: Luna 16 and 24, Apollo 11 low $K$ and high $K$, and Apollo 17 orange glass (Heiken et al, 1991). In the following discussion, we consider the implications for exosphere models of a $\mathrm{Mg}$ abundance in the regolith of $5 \%$ by number (consistent with the mean of the Apollo 11 and Luna measurements) and $8.6 \%$ by number, consistent with Apollo 17 orange glass.

\section{Sodium and potassium}

The potassium map obtained on January 17, 2008, at the McMath-Pierce solar telescope had 78 pixels in the illuminated portion of the planet. Zenith column abundances, along the normal to the planet strface, were calculated from observed line-of-sight abundances for a Chamberlain exosphere. Although this is not an exact model, it does remove the line of-sight effects given the assumption of a locally uniform exosphere. The average zenith column abundance of $\mathrm{Na}$ in the northern hemisphere was $4.4 \times 10^{10}$, and that in the southern hemisphere was $3.3 \times 10^{10}$ : the average zenith $K$ abundance in the northern hermisphere is $7.5 \times 10^{8}$, whereas that in the southern hemisphere is $1,3 \times 10^{9} \mathrm{~cm}^{-2}$. Since the noise-equivalent column for $\mathrm{K}$ is about $7 \times 10^{8}$, most of the $\mathrm{K}$ measurements in the northem hemisphere are consistent with noise, so only an upper limit is determined except for an area near the equator. From the zenith column abundance ratios per pixel, the average $\mathrm{Na} / \mathrm{K}$ ratio in the north, excluding pixels for which $K$
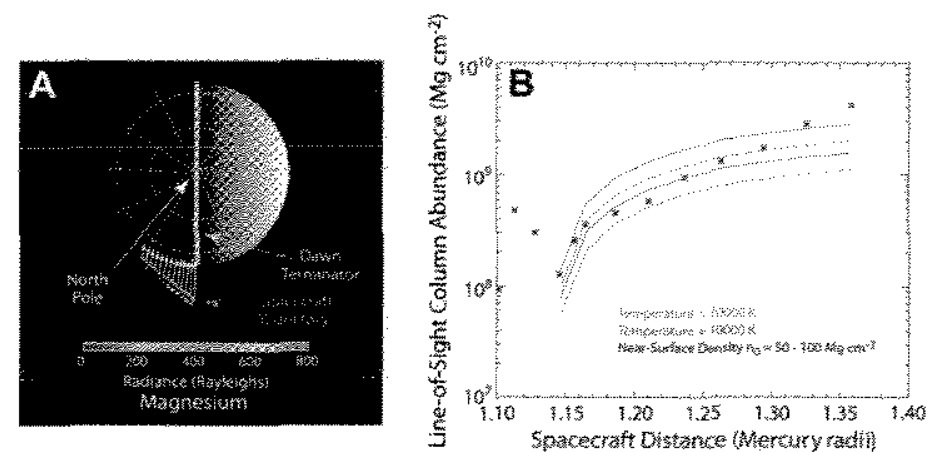

Fig. 7. (A) Hilustration of the geometry of the near-dawn terminator observation. The arrows show the direction of the Uvvs line of sight during each observation, and the colot tepresents the observed intensity, The observations were approximately in the equatetial plane. (B) Models fit to the near-terminator data indicate a best-fit solution at a temperature of $35,000 \mathrm{k}$ and density $\mathrm{n}_{0}$ of $75 \mathrm{~cm}^{-3}$; however, we show models at temperatures af $10,600 \mathrm{~K}$ and $70,000 \mathrm{k}$, respectively, each at sur and $100 \mathrm{~cm}^{3}$. Each inowidual data point $(*)$ is obtaned at a different distance behind the teminator, with those at a larger spackeraft distance from the phanet closer to the terminator. As the spacecraft moves toward the dawn terminator a longer path length is observed, and the path intersects less shadow. The nolse-equivalent column is

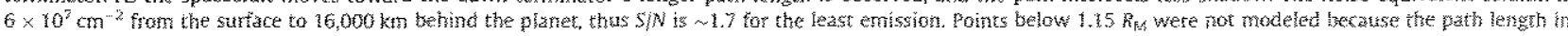
sunlight was too small The best-fit ternperature decreases and the best-fit surface number density incteases as the spaceraft approaches the termiriator (dawn). There aoes

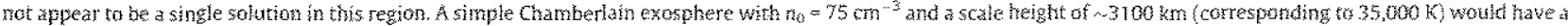
column abundance of $2,3 \times 10^{10}$ atems chn ${ }^{2}$.

Table 4

Model abundance of elements for Mercury surhate materials and abundances in selected tunar soils.

\begin{tabular}{|c|c|c|c|c|c|c|}
\hline specits & 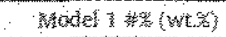 & $\operatorname{lin} 160$ & 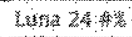 & 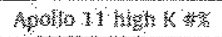 & 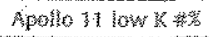 & 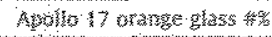 \\
\hline $\mathrm{Cs}$ & $2.15(1.3)$ & 4.9 & 4.7 & 4.4 & $4,4,4$ & 3. \\
\hline Mg . & 506 & 53 & 5.9 & 42 & 40 & 8.6 \\
\hline $\mathrm{Na}$ & $0.34(0,35)$ & 0.27 & 0,22 & 0.39 & 0.31 & 0.28 \\
\hline K. & $0.080 .02)$ & 0 of & & 0.18 & 0.03 & $0,04 s$ \\
\hline
\end{tabular}


is at noise-equivalent column, is 48.5 . The average $\mathrm{Na} / \mathrm{K}$ ratio in the south, also excluding pixels for which $\mathrm{K}$ is noise-equivalent column, is 22 where the $S / N$ in $K$ is $5-10$.

Note that historical data records give the ratios of line-of-sight column abundances. To facilitate comparisons, we compute these ratios as well even though they have line-of-sight effects. The line-of-sight average $\mathrm{Na}$ abundance was $9.9 \times 10^{10}$ in the northern hemisphere and $8.2 \times 10^{10}$ in the southern hemisphere. The aver age $\mathrm{K}$ line-of-sight abundance in the northern hemisphere was $1.8 \times 10^{9}$, and that in the southern hemisphere was $2.6 \times 10^{\circ} \mathrm{cm}^{-2}$. The average line of sight values are roughly twice those of zenith column values. The very large $\mathrm{Na} / \mathrm{K}$ ratio in the northem hemisphere reflects the fact that the $K$ abundance is very low in the northern hemisphere at this time. More interesting is the spatial distribution of $\mathrm{K}$. In the northern hemisphere $\mathrm{K}$ is almost entirely confined to within $30^{\circ}$ of the equator, whereas in the southern hemisphere $\mathrm{K}$ is mostly south of $30^{\circ} \mathrm{S}$.

Berezhnoy and Klumov (2008) concluded that for an impactvaporization source of the exosphere of Mercury, the ratio of $\mathrm{Na}$ atoms to all $\mathrm{Na}$ in the exosphere (atomic and molecular) is 0.7 . whereas the ratio of $K$ atoms to all $K$ is 0.4 . If we assume that these ratios hold for all source processes, and the average ratio is most representative of source processes, then the $\mathrm{Na} / \mathrm{K}$ ratio in the exosphere can be approximated as

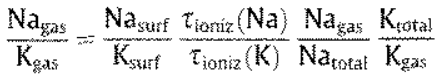

where $\mathrm{Na}_{\text {gas }} / \mathrm{K}_{\text {gas }}$ is the measured exospheric ratio (37), $\mathrm{Na}_{\text {gats }} / \mathrm{Na}_{\mathrm{t} t \mathrm{ata}}$ $=0.7$, and $K_{\text {gas }} / K_{\text {rotal }}=0.4$ from Berezhnoy and Kumov (2008). Given photo-ionization lifetime of $\mathrm{Na}$ from Huebner et al. (1992) and that for $K$ from Fulle et al. (2007) (Table 2), we derive the ratio of abundances in the regolith, $\mathrm{Na}_{\text {sur }} f K_{\text {sinf }}$.

$37=\mathrm{Na}_{\text {sur }} / \mathrm{K}_{\text {surf }}(3.75 \cdot 1.75)$

This last expression yields a ratio of $\mathrm{Na} / \mathrm{K}$ in the soil of approximately 5.6. For the ratio of $\mathrm{Na} / \mathrm{K}$ found in the southern hemisphere, where the $K$ abundance is above the noise-equivalent column, the observed atmospheric $\mathrm{Na} / \mathrm{K}$ ratio is 22 , yielding a $\mathrm{Na} / \mathrm{K}$ ratio in the surface of 3.4. The $\mathrm{K}$ content of Apollo 17 pristine orange glass is $0.045 \%$ by number $(625 \mathrm{~kg} / \mathrm{g}$ ). The $\mathrm{Na} / \mathrm{K}$ ratio in Apollo 17 pristine orange glass is 6.2 , and that in Luna 16 soil is 4.5. The average of our derived ratios of $\mathrm{Na} / \mathrm{K}$ in the soil is 4.5 and is therefore consistent with the abundance ratio in Luna 16 soil, for which the $\mathrm{K}$ abundance is higher than that in Apolio 17 orange glass but lower than that for high-K Apollo 11 lunar samples. The $\mathrm{Na/K}$ ratio derived from the northem hemisphere is consistent with Apollo 17 orange glass, a pyroclastic glassy deposit.

Photon-stimulated desorption has been shown to be an important, if not dominant, source of alkalis in the lunar and mercutian exospheres feg. Madey et al., 1998; Madey and Yakshinskiy, 1997; Yakshinskiy and Madey, 1999, 2004, 2005). Potter and Morgan
(1997) showed that the variations of $\mathrm{Na}$ and $\mathrm{K}$ in Mercury's exosphere are correlated and depend on the flux of solar ultraviolet (UV) radiation. Their ratios of $\mathrm{Na} / \mathrm{K}$ in the timeframe December 6-10, 1990, varied from 130 to 260; these are much higher than found here but probably included line-of-sight effects and also may indicate that low values of $\mathrm{K}$ abundance in the exosphere are consistent with noise-equivalent column. Potter et al. (2002) found an average $\mathrm{Na} / \mathrm{K}$ ratio in Mercury's exosphere of about 100. There were three dates reported in that paper on which the $\mathrm{Na} / \mathrm{K}$ ratio was most similar to the one found here: January 11 , 1998 (67.7), April 26, 1999 (66.3), and May 2, 1999 (69.5). We have included the observations of Potter et al. (2002) and our observations in Table 5 along with orbital distance from the Sun, true anomaly angle, heliocentric radial velocity, g-value of $\mathrm{Na}\left(\mathrm{D}_{1}+\mathrm{D}_{2}\right)$, $\mathrm{Na} / \mathrm{K}$ radiation acceleration $\left(\mathrm{cm} \mathrm{s}^{-2}\right)$, and $\mathrm{F} 10.7$. The $\mathrm{F} 10.7$ index is derived from the $10.7 \sim \mathrm{cm}$ radio flux, which has been shown to be correlated to the solar Lyman $\alpha$ flux and is a standard proxy for solar ultraviolet (UV) flux. The average value of $F 10.7 /(\mathrm{Na} / \mathrm{K})$ is 14.5 . regardless of whether 10.7 is high or low. The values of $\mathrm{Na} / \mathrm{K}$ ratio vs. Lyman $\propto$ flux nomalized to the heliocentric radial distance (Fig. 8) give a correlation coefficient of 0.66 , which implies a weak relationship between $\mathrm{WV}$ radiation and the $\mathrm{Na} / \mathrm{K}$ ratio in the exosphere (Fig. 8). The values of Lyman $\alpha$ flux (photons $\mathrm{cm}^{-2} \mathrm{~s}^{-1}$ ) in Table 5 are from the Laboratory for Atmospleric and Space Physics (LASP) Interactive Solar IRradiance Datacenter (LSIRD) website (http://asp.colorado.edu/LSIRD/) (Snow et al., 2005) and have been rotated to the orbital position of Mercury for a solar rotation rate of 27 days (disk average) and the phase angle given in Table 5. We conclude that the solar UV lux provides an important source of alkalis to the exosphere but cannot be the only source. The dependence on UV flux for the $\mathrm{Na} / \mathrm{K}$ ratio implies that $\mathrm{Na}$ and $\mathrm{K}$ vary differently with UV flux.

\subsection{Magnesium}

\subsubsection{Impact vaporization at the time of $\mathrm{M} 2$}

The magnesium observations reported here were obtained during the second MESSFNGER flyby on October 6, 2008. Mercury's orbital distance was $0.342 \mathrm{Au}$. We estimated the impact vaporization rate on this date using the planar impact approximation method (Melosh, 1989, chapter 4; Morgan and Killen, 1998; Killen and Sarantos, 2004), and we scaled the impact flux from Earth orbit measured by Love and Brownee (1993) to Mercury orbit following the mathematical formulation in Cintala (1992). We approximated the thermodynamic properties of the meteoroid impactors and the regolith using the "regolith" constants in Cintala (1992) and the impact parameters for Al onto enstatite given in Melosh (1989). Appendix $B$. Using this formulation the total vaporization rate at $R_{\text {orb }}=0.342 \mathrm{AU}$ is $2.7 \times 10^{7} \mathrm{~cm}^{-2} \mathrm{~s}^{-1}$ for impact of aluminum a proxy for asteroid composition) onto regolith, and the $\mathrm{Mg}$

Table 5

Observations of Nak and relevant plystcal parameters

\begin{tabular}{|c|c|c|c|c|c|c|c|c|c|c|c|}
\hline Date & $R_{S t i}(\mathrm{AU})$ & TA $(D)$ & Phase (") & ( $\left(\mathrm{ms} \mathrm{s}^{-1)}\right.$ & Whase $(10)$ & Na/K & Radiation accelerarim (Na) & $F 10.7$ & mak & $4 y \times 10^{81}$ & ly $01 k^{2} \times 10^{33}$ \\
\hline December 6,1990 & 0.355 & 2745 & 77 & -10.0 & 57.9 & 234 & 1692 & $22 \% 3$ & 105 & 5,74 & 4.1 \\
\hline December 7,1990 & 0,359 & 279.5 & 80 & -3.94 & 53.5 & 155 & 174.0 & 228 & 14.8 & 5.78 & 44,8 \\
\hline December \&, 1500 & 0.333 & 284.2 & 84 & -9.76 & 60.7 & 260 & 1776 & 230 & 8.9 & 5.81 & $46: 8$ \\
\hline December 9.1990 & 0.348 & $28 \mathrm{~s}$ & s祭 & -9.5 & 61.7 & 137 & 1802 & 2374 & 15.1 & $5 \times 2$ & 48,1 : \\
\hline Decentiber 10,1890 & 0.342 & 284.1 & 93 & $\sim 9.2$ & 62.1 & 130 & 181.3 & $200 \%$ & 18.5 & 5.82 & 49.8 \\
\hline jatruary 1 1998. & 0.424 & 129.5 & 62 & +7.8 & $34: 2$ & 67.7 & 99.9 & 1017 & 15.0 & 3 s. & $21 \%$ \\
\hline Aprol 26,1999 & 044 & 216.5 & 77 & -6.0 & 22.1 & 60.3 & 64.5 & 1058 & 159 & 4.18 & 212 \\
\hline May 2. 1999 & 0 卅10 & 235.5 & 56 & -8.3 & 37.9 & 69.5 & 110.7 & 1379 & 19.8 & 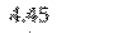 & 253 \\
\hline
\end{tabular}

Notes: $K_{6 x}$ o orbitat distance in $\mathrm{AU}$. $\mathrm{Y} A=$ rue anomaly angle. 


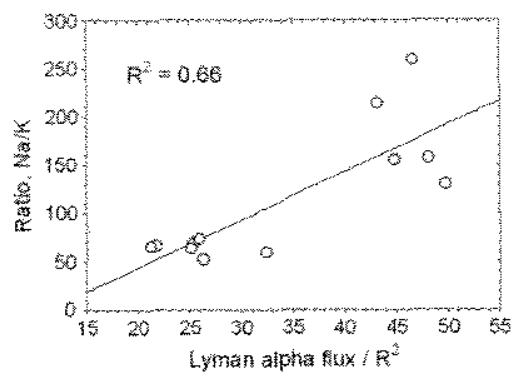

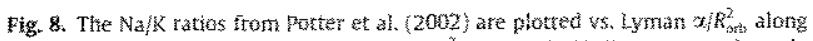
with that from this paper (data point at $L y \alpha / R_{0, w}^{z}=32$ ). The $\mathrm{Na} / \mathrm{K}$ ratio is moderately corretated with the fyman $\alpha$ radiation. We plot the averase Nalk ratio over the inuminated disk to avoid complications regarding scale-height effects of the dish and added noise caused by low-signal $K$ observations as the K decreases away from the planet. Athough a linear correlation coefficient of 0.66 does not represent a strong correlation, it indicates that $66 \%$ of the variation can be explained by a linear correlation between the ratio of Najk and Lyman o fux. However, our data point is much lowet thay those found earlier because we rejected $K$ values that have $S / N<1$. This indicates that although UN radiation is involved, other factors are effective in the ejection and loss processes.

vaporization rate is $2.3 \times 10^{6}$ atoms $\mathrm{cm}^{-2} \mathrm{~s}^{-1}$ for an $8.6 \%$ surface abundance of $\mathrm{Mg}$ or $1.3 \times 10^{6} \mathrm{~cm}^{-2} \mathrm{~s}^{-1}$ for a $5 \%$ abundance of $\mathrm{Mg}$.

In addition to the Cintala (1992) and Morgan and Killen (1998) analyses of meteoroid impact rates onto the surface of Mercury. several new estimates have been published. Notably, Borin et al. (2009) have estimated a meteoroid impact flux onto Mercury 170 times the Cintala rate. This of course has important implications concerning the exosphere. Killen et al. (2001) used the Cintala (1992) mathematical formulation tor transfer of material from Earth orbit to Mercury orbit with the Love and Brownlee (1993) interplanetary dust particle (IDP) flux rates and the Morgan and Killen (1998) impact vaporization code to estimate the magnitude of various contributions to the sodium exosphere and obtained an estimate of $20-30 \%$ of the sodium exosphere contributed by impact vaporization. Thus, an increase of the Love and Brownlee (1993) flux by a factor of only $3-5$ would supply the entire exosphere. Morgan et al. (1988) estimated that meteoroids supply up to $1.4 \times 10^{24} \mathrm{Na}$ atoms $\mathrm{s}^{-1}$ to the exosphere, or a factor of about 5 greater than the Cintala rate, and concluded that meteoroid vaporization can supply the full $\mathrm{Na}$ exosphete of Mercury. The main reason for the larger rate given by Morgan et al. (1988) is the use of a velocity distribution function from Southworth and Sekinina (1973). An impact flux 170 times the Cintala rate would either overwhelm the exosphere, or we would have to conclude that impact vaporization is aither less efficient than previously estimated, that impact vapor quickly condenses, leaving only $2 \%$ of the vapor in the exosphere, or that the vaporization products are not fully measured, possibly being in molecular form. The distribution of various elements in the exosphere appears to be inconsistent with uniform impact vaporization by micrometeoroids (e.g., Burger et al. 2010), mainly because of high-latitude enhancements, a dawn enhancement in $\mathrm{Ca}$, and rapid variability.

The Mg observations in Mercury's tail region were fit by a 15,000-50,000-K gas, which is much hotter than would be expected from direct impact vaporization. Although the temperature is not well constrained. and indeed the velocity distribution is ikely to be non-thermal, it is clear that a hot vapor is recuired to fit the data. Very hot $(30,000 \mathrm{~K}) \mathrm{Ca}$ atoms have been observed hn Mercury's exosphere from ground-based observations (Bida et al.. 2000; Killen et al, 2005) and were attributed to vaporization of calcium in molecular form with subsequent dissociation, which imparts additional energy to the atomic fragments. We suggest that the same process produces the hot Mg that we have observed in the tail region. The dissociation energy of $\mathrm{MgO}$ is $3.35 \mathrm{eV}$ (Murthy and Bagare, 1978). If dissociated by a Lyman a photon (10.2 eV) the products would have an excess energy of $6.8 \mathrm{eV}$ between them. If each fragment has $3.4 \mathrm{eV}$, then the equivalent temperature is $40,000 \mathrm{~K}$. If the gas temperature is $40,000 \mathrm{~K}$, the mean velocity of the gas is $5.2 \mathrm{~km} \mathrm{~s}^{-1}$, which is above escape velocity $\left(4.2 \mathrm{~km} \mathrm{~s}^{-1}\right.$ ). Thus those $\mathrm{Mg}$ atoms that are derived from dissociation of $\mathrm{MgO}$ will escape. Their lifetimes will be the photo-ionization lifetime (Table 6). The Mg ionization rate is $5.66 \times 10^{-7} \mathrm{~s}^{-1}$ at Earth (quiet Sun or $4.84 \times 10^{-6} 5^{-1}$ at Mercury during the second MESSENGER flyby. Thus the Mg photo-ionization lifetime was $2.0 \times 10^{5} 5$, or $57 \mathrm{~h}$. At a velocity of $5.8 \mathrm{~km} \mathrm{~s}^{-1}$, a Mg atom would travel 475 planetary radii on average before becoming ionized. The Hill sphere, where the gravitational field of the Sun dommates over that of Mercury, is at $\sim 81 R_{M}$. Therefore ionization is not a major loss process for $\mathrm{Mg}$ in the region that we observe. Note that even though the $\mathrm{Mg}$ atoms in the tail have very high velocities relative to the planet, the g-values, and hence the derived column abundances, only differ by $5 \%$ between that for a $\mathrm{Mg}$ atom at rest with respect. to Mercury $(g-v a l u e=0.317)$ and one traveling at $5 \mathrm{~km} \mathrm{~s}^{-1}$ antisunward $(g$-value $=0.300)$. Therefore the assumed g-values do not introduce a large error in the derived column abundances even if the assumed velocities are incorrect.

The fraction of $\mathrm{Mg}$ (atoms)/Mg(total) from impact vaporization at quenching was estimated by Berezhnoy and Klumov (2008) to be less than that of the alkali species. At $4000 \mathrm{~K}$, the equilibrium fraction of $\mathrm{Mg}$ to $\mathrm{MgO}$ is about 2 (Berezhnoy and Klumov, 2008), We asstme that half of the $\mathrm{Mg}+\mathrm{MgO}$ will condense, leaving a gas release rate of $0.7 \times 10^{6}<d n / d t<1.2 \times 10^{6}$ for $\mathrm{Mg}$ abundances of $5 \%$ and $8.6 \%$, respectively. If we assume that $30 \%$ of the impactderived $\mathrm{Mg}$ is in the form of $\mathrm{MgO}$, then the very hot portion of the $\mathrm{Mg}$ exosphere should have an impact vapor source rate of $0.3 \cdot 1.2 \times 10^{6} \mathrm{~cm}^{-2} \mathrm{~s}^{-1}=3.6 \times 10^{5} \mathrm{~cm}^{-2} \mathrm{~s}^{-1}$ tor an $8.6 \% \mathrm{Mg}$ abundance in the regolith or $2 \times 10^{5} \mathrm{~cm}^{-2} \mathrm{~s}^{-1}$ for a $5 \%$ abundance, using the vapor code described it Morgan and Killen (1998). The observed column is estimated to be $7 \times 10^{9} \mathrm{~cm}^{-2}$ normal to the surface: If the exosphere is that portion from the surface to the Hill sphere ( 81 planetary radii) and the Mgatoms have a mean velocity of $5 \mathrm{~km} \mathrm{~s}^{-1}$, then the lifetime of the Mg atom in the exosphere is $4 \times 10^{4} \mathrm{~s}$. Then if the production rate of $\mathrm{Mg}$ is $6.75 \times 10^{5} \mathrm{~s}^{-1}$, and the lifetime is $4 \times 10^{4} \mathrm{~s}$, we would expect to see a column of $2.7 \times 10^{10} \mathrm{Mg}$ atoms. Given that we see $26 \%$ of that, we conclude that this is the fraction of the vapor initially in the form of MgO that was dissociated to produce the very hot atomic $\mathrm{Mg}$ observed. This inference is consistent with the result from Berezhnoy and Klumov, namely that $30 \%$ of the vapor is in the form of MgO. We conclude that impact vaporization of $\mathrm{Mg}$-bearing minerals can pro duce the observed $\mathrm{Mg}$ tail given an abundance of $\mathrm{Mg}$ in the regolith of $5-8.6 \%$, if roughly half of the vapor condenses and $30 \%$ of the vapor is in the form of Mgo as estimated by Berezhnoy and Kiumov (2008). This relies on the assumption that the observable lifetime of $\mathrm{Mg}$ is the lifetime of the atom to the Hill sphere.

Table 6

fonization rates for he observed species

\begin{tabular}{|c|c|c|c|}
\hline Spoties. & 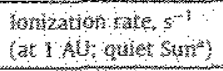 & $\begin{array}{l}\text { Wonduph rates } \\
\text { tat }\end{array}$ & 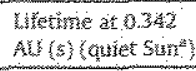 \\
\hline $\mathrm{Na}$ & $3.99 \times 10 \%$ & $5.52 \times 10 \%$ & $1.95 \times 10^{6}$ \\
\hline $\mathrm{Ms}$ & $5+6 \times 10^{-7}$ & $100 \times 10$ & $20 \% \times 10^{5}$ \\
\hline Ca & $70 \times 10^{-5}$ & $8.8 \times 10^{n}$ & $1.67 \times 10^{3}$ \\
\hline k & $2,2 \times 10^{-5}$ & $24 \times 10^{-\frac{3}{*}}$ & $53 \times 10^{3}$ \\
\hline
\end{tabular}

${ }^{2}$ lomizution rates depend on vhe solar Extreme UV flux, which depends on the solar cycle. 
3.3.2. Ion sputtering at the time of $\mathrm{M} 2$

Sputter yields of $\mathrm{Mg}$ from $\mathrm{MgO}$ by low-energy $\mathrm{He}$ and $\mathrm{Ar}$ lon beams were measured as a function of ion energy by Hine at al. (2007) and fit to the following equations:

$Y_{\text {Һ̆ }}=a\left(\sqrt{E / E_{0}}-1\right)$

where $Y_{\text {He }}$ is the $\mathrm{MgO}$ sputter yield from incoming He tons, $a=0.191$, and $E_{0}=241 \mathrm{eV}$;

$Y_{\mathrm{Ar}}=a\left(1-\sqrt{E_{0} / E}\right)^{5 / 2}\left(1+b\left(\sqrt{E / E_{0}-1}\right)\right)$

where $Y_{A r}$ is the sputter yield of $\mathrm{MgO}$ by impacting Ar ions, $a=0.0644, b=7.61$, and $E_{0}=36.5 \mathrm{eV}$. These measurements were made for $E<460 \mathrm{eV}$; however, we will employ the equation to estimate yields by solar wind ions. The sputter yield of $\mathrm{Mg}$ by 3.3-keV He ions in the solar wind would therefore be about $0.5 /$ ion.

Ignoring for the moment highly charged ions, which normally comprise less than $1 \%$ of the solar wind, and assuming that He ions are $4 \%$ of the solar wind, the solar wind yield would be

$\frac{d(\mathrm{Mg})}{d t}=0.02 f_{\text {SW }} \mathrm{fMg}_{\mathrm{Mg}}$

where $f_{\mathrm{st}}$ is the solar wind flux onto the surface of Mercury and $f_{\mathrm{Mg}}$ is the number fraction of $\mathrm{Mg}$ in the soil. We estimate that the solar wind flux onto the surface of Mercury during the second flyby was $10^{25}$ ions $s^{-1}$ (e.g., Benna et al., 2010), although this may be an optimistic estimate (e.g., Satantos et al., 2007). If we assume that the fraction of Mg in Mercury's regolith is $8 \%$, then the sputter yield is about $1.6 \times 10^{22}$ atoms $s^{-1}$ or a planetwide average of $2 \times 10^{4} \mathrm{Mg} \mathrm{cm}^{-2} \mathrm{~s}^{-1}$. If the lifetime of the $\mathrm{Mg}$ atom to the Hill sphere is $4 \times 10^{4} \mathrm{~s}$, the column from sputtering would be about $8 \times 10^{8} \mathrm{Mg} \mathrm{cm}^{-2}$, or about $10 \%$ of the observed column. Although the sputter yield averaged over the planetary surface is two orders of magnitude less than the estimated hypervelocity impact yield, the local yield in areas of open fields may be comparable, especially at times of enhanced solar wind fux. The local proton flux to the surface can be as high at $10^{11}$ ions $\mathrm{cm}^{-2} \mathrm{~s}^{-1}$ and averages $10^{8}$ in the open areas (Benna et al., 2010). With a yield per ion of 0.02 $f_{\mathrm{N} \text { g }}$ or $\sim 0.002 f_{\mathrm{sw}}$ the local sputtered Mg rate averages about $2 \times 10^{5} \mathrm{~cm}^{-2} \mathrm{~s}^{-1}$ in the cusp regions during the first MESSENGER flyby when the magnetosphere was quiet and the interplanetary magnetic field (IMF) was northward, impeding solar wind access to the surface. The sputter yield may be as high as 0.2 /ion, in which case the sputtered $\mathrm{Mg}$ rate would be about $(1-2) \times 10^{6} \mathrm{~cm}^{-2} \mathrm{~s}^{-1}$ in the cusp regions during the first MESSENGER flyby. This local rate would be comparable to the impact vaporization rate and would produce hot atomic Mg. If this ion-sputter yield adds to the impact vaporization yield, then the local yield could produce local enhancements equal to 10 times the observed average column, as observed by MESSENGER during the thitd flyby (McClintock et al., 2009). The estimated sputtering source is therefore a small fraction of the total Mg exosphere but could be important for populating the tail region.

Because the disturbed solar wind can be comprised of enhanced fractions of heavy elements, for instance up to $30 \%$ He ions (Wang. 2008), sputtering by highly charged heavy ions may play an important role at Mercury (Kallio et al., 2008). Sputter yields by highly charged ions are known to be significantly enhanced over those by singly charged ions, especially in insulators. This effect is known as "potential sputtering" and has been extensively discussed in the literature (e.g. Kallio et al. 2008). Although the charge-state effect is not as great in highy ionic oxides such as Mgo, there is still a significant charge-state effect (Hayderer et a. 200 ). If we can corre late enhanced ion sputtering with solar energetic particle (SEP) events at Mercury, we may be able to determine whether the highly charged tons are an important source of sputtered atoms.
Additional laboratory work on sputter yields by highly charged ions is needed to more fully understand this process.

\subsubsection{Estimate of photon-stimulated desorption of $\mathrm{Mg}$}

Magnesium can be desorbed from MgO by 265-nm laser pulses (joly, 2002), and PSD yields of Mg from Mgo are comparable to those for Na. Although MgO comprises about $15-26 \%$ of pyroxene, and the pyroxene abundance is about $40-60 \%$ for mare basalts on the Moon, the $\mathrm{Mg}$ is present as a silicate. Therefore the PSD yields for Mg from Mercury's surface minerais is highly uncertain at the present. Mg would be desorbed by PSD only if a significant amount of Mgo were re-deposited on the surface as a result of impact vaporization.

\section{Discussion}

Potter et al. (2002) found that the ratio of sodium to potassium in the exosphere of Mercury was highly variable and averaged $100 \pm 20$, much larger than values observed elsewhere in the Solar System (Table 7). The $\mathrm{Na} / \mathrm{K}$ ratio in the lunar exosphere is close to that in the lunar crust. We will argue that the Na/K ratio in Mercury's exosphere is in fact much larger than that ratio in the regolith, and that very large ratios of $\mathrm{Na} / \mathrm{K}$ in Mercury's exosphere may be due to very low abundances of $k$ in the exosphere, where measutements are dominated by noise.

The $\mathrm{Na} / \mathrm{K}$ ratio in the exosphere of the Moon is in the range $4.4-$ 6 , not far from overall average ratio of $\mathrm{Na} / \mathrm{K}$ in the surface lunar rocks, which is in the range $7-9$. potter et al. (2002) found that radiation acceleration losses were not sufficiently different for sodium and potassium to explain the $\mathrm{Na} / \mathrm{K}$ high ratio. They proposed that the photo-ionization loss and recycling rates were sufficientiy different for sodium and potassium to account for the high ratio. The higher mass of the potassium atom relative to sodium 39 vs. 23) resuits in a smaller scale height and a larger gyroradius for potassium relative to sodium, which may result in more rapid net loss of potassium from the planet. However, Sarantos (2005) considered relative loss rates of $\mathrm{Na}$ and $\mathrm{k}$ photoions to the solar wind and concluded that the difference was too small to explain the variations in the $\mathrm{Na} / \mathrm{K}$ ratio in the exosphere. Our results show that the $\mathrm{Na} / \mathrm{K}$ ratio in Mercury's exosphere is in the range $22-49$, where the ratios are taken only where the observations are above the noise-equivalent column.

A possible explanation for the large variation in the published $\mathrm{Na} / \mathrm{K}$ ratios at Mercury is the use of improper $g$-values. This is certainly the case for the high value of $\mathrm{Na} / \mathrm{K}$ teported in the Earth's atmosphere (Cault and Rundle, 1969). Although the g-values were scaled for the radial velocity of Mercury at the time of the observation, there are two effects that were not taken into account. First, the radial velocity not only affects the continum at the rest frequency of the atom in the atmosphere of Mercury, but it affects the multiplet structure, since each transition is independently af-

Table 7

Sodim to porassinu ratios by number in the Solar 5ystem.

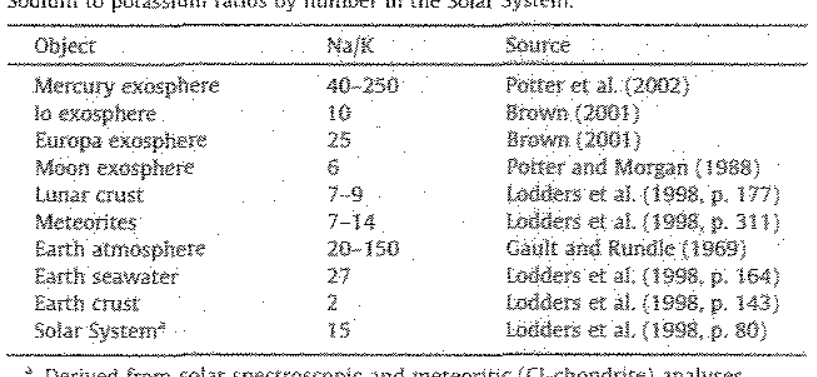

${ }^{3}$ Berived from solar spectoscoplc and meteontic (clehondrite) analyses. 
fected by the structure of the solar spectrum. Secondly, the velocity of the atom inside the atmosphere was not taken into account in the data reduction. The radial velocity of the bulk atmosphere may vary with the solar zenith angle and the viewing geometry. Third, the K emission is weak and the uncertainty in the abundance is large. Nevertheless there are valid explanations for a variable $\mathrm{Na}$ / $\mathrm{K}$ ratio in the exosphere of Mercury. The questions here are why is the source rate variable and why is it different for $\mathrm{Na}$ and for $\mathrm{K}$.

There is a moderate correlation between $\mathrm{Na} / \mathrm{K}$ and Lyman $\alpha$ flux, with a correlation coefficient of 0.6 . The measured ratio is either large (on the order of 150-250) for Lyman $\propto$ greater than $5 \times 10^{11}$ photons $\mathrm{cm}^{-2} \mathrm{~s}^{-1}$ or small ton the order of $<60$ ) for Lyman a less than $5 \times 10^{11}$ photons $\mathrm{cm}^{-2} \mathrm{~s}^{-1}$. One explanation is that the rates of supply of volatiles to the extreme surface, or the uppermost few monolayers, and thus to the exosphere, are diffusion-limited, and the diffusion rate for $K$ is less than the diffusion rate for $\mathrm{Na}$ (Killen and Sarantos, 2004). Diffusion of atoms from the interior of grains to the extreme surface, or the topmost few monolayers, is required in order to repopulate the layers from which PSD and ion sputtering can eject atoms (Killen and Sarantos, 2004). Diffusionlimited supply is a well-known phenomenon in sputtening (e.g. Roth, 1983). The ate at which $\mathrm{Na}$ and $\mathrm{K}$ diffuse to the surface of grains of sizes $1 \mu \mathrm{m}$ to $1 \mathrm{~m}$, at temperatures found on the surface of Mercury, was calculated by Killen and Sarantos (2004) using diffusion data from Nyquist et al. (1979). Note that this is a fundamentally different problem than that considered by Cheng at. (1987) and by Killen and Morgan $(1993,1994)$, who treated Knudsen flow from depth. Killen and Sarantos (2004) showed that the volatiles initially near the rims of grains are rapidly depleted, and that the rate at which a trace volatile is delivered to the extreme surface of a grain, where it can be acted upon by either photons or ions, is not only a function of temperature but also of grain size and time since the grain was first exposed to space weathering. In other words, there is a maximum ejection rate for a particular element set by the rate at which that element can diffuse to the extreme surface of the grain where it can desorb, and this fate is a function of grain size, phase (crystalline or amorphous), tempera- ture, and weathering. We call this the diffusion-limited supply rate. of course, meteoroid impacts can vaporize entire grains or boulders, depending on the impactor size, and this must be factored into a global solution.

Fig. 9 shows that for a diffusion coefficient $D=10^{-15}\left(\mathrm{~cm}^{2} \mathrm{~s}^{-1}\right)$ all grains smaller than about $0.1 \mathrm{~cm}$ in radius will be able to supply the atmosphere at the required rate given by the known exosphere loss rate, assumed here to be $10^{7} \mathrm{~cm}^{-2} \mathrm{~s}^{-1}$, until half of their solute is lost. For progressively larger grains, a lesser fraction of solute will be lost at the required rate, and thereafter the rate will drop exponentially. This result is completely consistent with that of kil len (1989), who determined that diffusion out of glass grains is too fast and diffusion from a semininfinite slab of crystalline mineral is too slow to maintain the exosphere. This is because small, hot grains, and glass grains, lose their volatiles rapidly, and large, crys. talline grains or a slab lose their volatiles at a much slower rate. For smaller values of the diffusion coefficient, progressively smaller grains will be unable to deliver their solute to the extreme surface at the required rate. One-centimeter-fadius spheres can maintain a maximal thermal vaporization rate at the subsolar point (at perihelion) if they are glass. At aphelion, even mineral grains can maintain the maximal thermal loss rate for the lifetime of the grain on the surface.

Given a fractal distribution of grain sizes, and a distribution of temperatures on the surface, on average the exosphere is maintained at the observed rate (Killen and Sarantos, 2004). How does this explain the observed variability?

Boundaries on the diffusion coefficients for $\mathrm{Na}$ and $\mathrm{K}$. respectively, are shown in Fig. 9 for glass from the leftmost boundary to the right-pointing arrow and for minerals from the rightmost boundary to the left-pointing arrow. Note that the expected $\mathrm{K}$ diffusion coefficients are in the region where the fraction of solute that will degas at a rate of $10^{7} \mathrm{~cm}^{-2} \mathrm{~s}^{-1}$ is a steep function of the diffusion coefficient, $D$ (and thus of temperature). Suppose that an event occurs that causes an increased yield of alkalis to the exosphere, such as a coronal mass ejection (e.g., Kallio and Janhunen, 2003). Fig. 9 shows that $\mathrm{Na}$ atoms will be able to fill holes created by

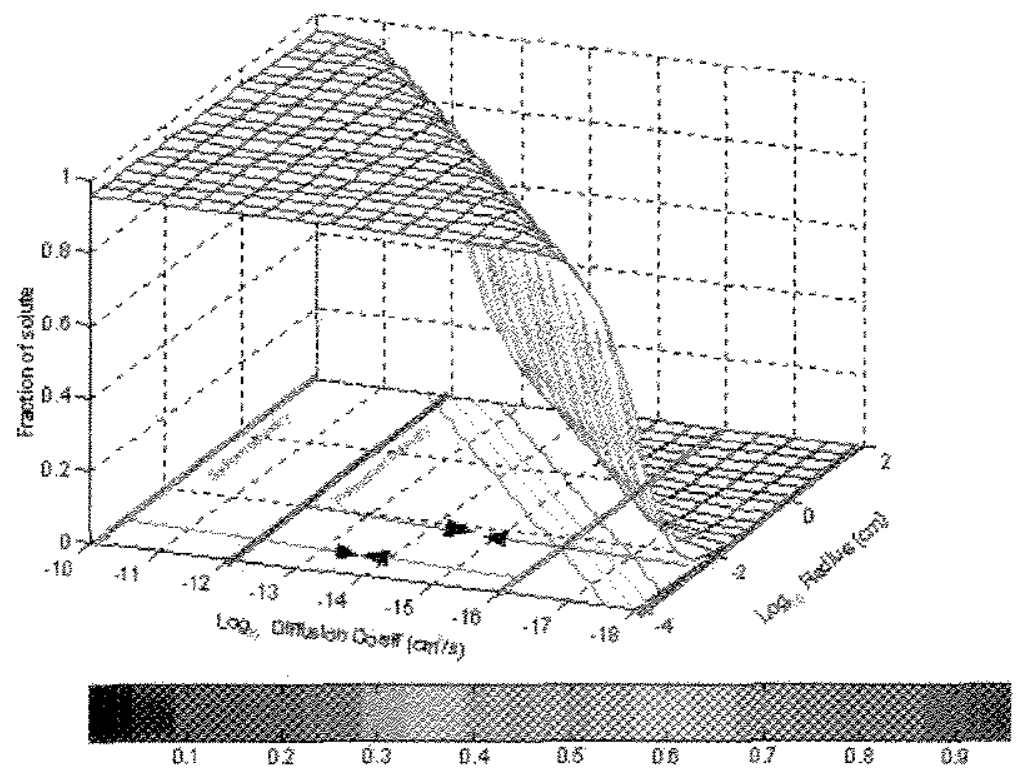

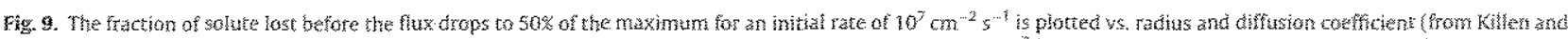

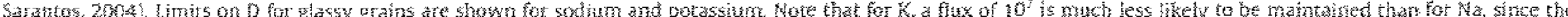

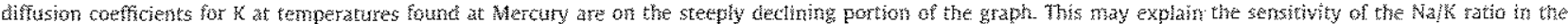
atmosphere to extemal forcing that is independent of surface temperature, such as ion sputtering 
desorption much more rapidly than will $\mathrm{K}$ atoms. All grains larger than 1 um can supply $\mathrm{Na}$ at a rate of $10^{7} \mathrm{~cm}^{-2} \mathrm{~s}^{-7}$, but only grains larger than $100 \mathrm{\mu m}$ can supply $\mathrm{K}$ at that rate. The fraction of solute lost per unit time at a given temperature is much greater for $\mathrm{Na}$ (pink boundary) than for $\mathrm{K}$ (blue boundary). The region of interest for Mercury is between the bold blue lines on the log diffusion coefficient scale for $\mathrm{K}$ and between the bold pink lines for $\mathrm{Na}$. Thus, the $\mathrm{Na} / \mathrm{K}$ ratio in the atmosphere may increase after an energetic event in which most surface atoms are desorbed because the Na sites will be rapidly refilled, but the $\mathrm{K}$ sites will take more time to recover.

\section{Conciusions}

The existence of very hot refractory species in Mercury's exosphere is consistent with ejection of molecules from the surface, with subsequent dissociation into hot fragments. The hot $\mathrm{Mg}$ tail is consistent with a surface abundance of $5-8 \% \mathrm{Mg}$, if $30 \%$ of impact-vaporized $\mathrm{Mg}$ remains as $\mathrm{MgO}$ at quenching and half of the impact vapor condenses. All of the ejected Mgo molecules are assumed to be dissociated to populate the tail region with the observed hot atomic Mg. Globally, ion sputtering is not a major source of $\mathrm{Mg}$, but locally the sputtered source may be comparable to or greater than the impact vapor source. Photons can desorb $\mathrm{Mg}$ from MgO, so PSD may be an important source for Mg on the dayside if Mgo is deposited on the surface by some process such as impact vaporization of a regolith mineral. $\mathrm{Mg}$ has not been observed on the dayside of Mercury to date, and because of the sparsity of data we cannot determine the global distribution of $\mathrm{Mg}$ at this time. Nonetheless, the terminator data show that the temperature of the $\mathrm{Mg}$ gas decreases and the $\mathrm{Mg}$ number density at the surface increases as the dawn terminator is approached.

We conclude that the $\mathrm{Na}$ and $\mathrm{K}$ in Mercury's exosphere can be derived from a regolith composition similar to that Luna 16 lunar soil in which the abundances are 0.0027 for $\mathrm{Na}$ and 0.0006 for $\mathrm{K}$ (Heiken et al., 1991). The variability of $\mathrm{Na}$ and $\mathrm{K}$ in the exosphere is shown to be weakly correlated with the solar UV flux at Mercury with a correlation coefficient of 0.66 . This variability of the $\mathrm{Na} / \mathrm{K} \mathrm{ra}$ tio may be related to the differences in diffusion from the interiors of regolith grains to the extreme surface where they are ejected by PSD or ion sputtering. The variability in the exosphere is larger than local differences in the $\mathrm{Na} / \mathrm{K}$ abundance, if they are similar to differences between Apollo orange glass and Luna 16 samples. Since Caloris basin was visible in the northern hemisphere between $23^{\circ}$ and $58^{\circ}$ from the sub-Earth longitude on the illuminated portion of the disk, and exospheric potassium was found to be weak in that region, we conclude that $k$ is not enhanced over the Caloris basin at that time, in contrast to the findings of Sprague et al. (1990). Very large values of $\mathrm{Na} / \mathrm{K}$ are indicative of small abundances of $\mathrm{K}$ and are influenced by noise.

Observations of $\mathrm{Mg}$ in the near-terminator region appear to show that the surface number density increases and the temperature of the gas decreases as the dawn hemisphere is approached. A single model does not match all of the data, indicating the existence of a non-uniform exosphere. New models of the Mercury magnetosphere derived from MESSENGER observations should make it possible to test loss and recycling rates. The newly discovm ered element in Mercury's exosphere, Mg, clearly is promoted into the exosphere by processes that are different from those ejecting the more volatile species, $\mathrm{Na}$ and $k$. Whereas the temperature of the volatile species, Na and $K$, has been shown to be approximately that expected for a PSD source, or $1200 \mathrm{~K}$, the temperature found for Mg is on the order of tens of thousands of degrees. Na and Kexist in an extended anti-sunward tail because they are accelerated by radiation pressure due to the strong resonance lines in the visible region of the solar spectum. There is no such strong reso- ance line for $\mathrm{Mg}$ in the visible region where the solat flux is strong; hence radiation pressure is negligible for Mg. Nevertheless we measured $\mathrm{Mg}$ in the anti-sunward tail. The conclusion is that the source process promoting $\mathrm{Mg}$ to the exosphere produces the hot $\mathrm{Mg}$. This is very similar to the conclusion that we have found for $\mathrm{Ca}$ (killen et al., 2005). These refractory species are ejected into the exosphere by a process that imparts $\sim 2 \mathrm{eV}$ to the $\mathrm{Mg}$ atom and $\sim 3 \mathrm{eV}$ to the $\mathrm{Ca}$ atom. We do not yet have enough data to determine the global distribution of Mg. However, the data shown here. in indicate that the $\mathrm{Mg}$ is non-uniform.

\section{Aciknowledgments}

R.M. Killen and R.J. Vervack, Jr., are Participating Scientists on NASA'S MESSENGER mission to Mercury and were supported by NASA Grants NNX07AR78G and NNX07AR63G, respectively. The $\mathrm{Na}$ and $\mathrm{K}$ observations were obtained with the McMath-pierce telescope at Kitt Peak operated by the National Solar Observatory under contract with the National Science Found ation. These observations were supported in part by the NASA Planetary Astronomy Program under Grant NNX08AP65G. We thank Claude Plymate for valuable observing support. Observations of $\mathrm{Mg}$ were obtained by the MASCS instrument on the MESSENCER Spacecraft. We acknowledge support of The Johns Hopkins University. Applied Physics Laboratory for MESSENGER mission operations and the MESSENGER science team for valuable discussions.

\section{Appendix A}

The comparison of data to the Chambetlain model is achieved by first generating model predictions of the exosphere over a tange of temperatures and densities along the line of sight for the observations. Then the model-predicted column abundances are compared to the data in a least squares analysis to retrieve the temperature and density. The analysis can be broken down into categories for each observation regime.

\section{A.1. Tail-sweep observations}

For the tail-sweep observations the spacecraft is not in the shadow of the planet. The line of sight oscillates up and down relative to the planet's equatorial plane, causing it to intersect the planet's shadow for some of the observations and not intersect the shadow for others. A subset of observations was selected where the lines of sight were pointing near the equatorial plane and passed through the shadow of the planet. Refer Fing to Fig. 4 , the column abundance along the portion of the line of sight in the dawn-side hemisphere, $S_{2}$, was calculated over a range of temperatures and densities using $R_{2}$ and $\theta_{2}$ as inputs to the Chamberlain model and with $s_{z}$ extending from $k_{z}$ to infinity. The column abundance along the portion of the line of sight in the dusk-side hemisphere, $S_{1}$, was determined over a range of temperatures and densities by calculating the colum abundance from $k_{3}$ to infinity in the direction of the spacecaft and from $R_{s}$ to infinity and then taking the difference between the two. A least squares analysis was performed over temperature and densiry for both the dusk-side and dawn-side lines of sight. For a single temperature, the Chamberlain-predicted columa abundances from the dawn side hemisphere for the en tire range of densities were added one by one to each of the column abundances from the dusk-side hemisphere over their range of densities for the same temperature, This was done for each of the subset of observations and compared to the corresponding set of measured column abundances. The difference is 
$D\left(T, \rho_{\text {cà }}, \rho_{\text {dusk }}\right)=\sum_{i=1}^{\mathrm{n}}\left[N_{i}-M\left(T, \rho_{\text {dawn }}, \rho_{\text {dusk }}\right)^{2}\right.$

where $N$ is the measured column abundance. $M$ is the modei-predicted column abundance at a specific temperature $(T)$, dawn-side density ( $\left.\rho_{\text {dawn }}\right)$, and dusk-side density ( $\left.\rho_{\text {dusk }}\right)$, and the sum is over the number of observations $(n)$. The result is a three-dimensional matrix of $D$ where the minimum value is interpreted as the best fit of the data to the model.

\section{A2. Fantall observations}

When the spacecraft is in shadow, the line of sight can only exit the shadow. The column abundance was determined over a range of temperatures and densities along the line of sight from the point where it exits the planet's shadow to infinity. The fantail observations were analyzed by comparing all of the fantail data with the corresponding Chamberlainmpredicted columa abundances over temperature and density. The difference is given by

$D(T, \rho)=\sum_{i=1}^{n}\left[N_{i}-M(T, \rho)\right]^{2}$

where $N$ is the measured column abundance, $M$ is the model-predicted column abundance at a specific temperature $(T)$ and density $(\rho)$, and the sum is over the number of observations $(n)$. The result is a two-dimensional matrix of $D$ where the minimum value is interpreted as the best fit of the data to the model.

\section{A.3. Terminator observations}

When the spacecraft is not in the planet's shadow but the field of view intersects the shadow and then intersects the planet, the Chamberlain column abundance over a range of temperatures and densities was calculated from the point of line-of-sight intersection with the shadow to infinity (this column will pass through the spacecraft) and from the spacecraft to infinity (this will be in the direction opposite to the line of sight). The second quantity was subtracted from the first, and the same least squares analysis was performed as for the fantall observations.

\section{References}

Benna, Mĩ., and 17 colleagues, 2010. Modeling of the magnetosphere of Mercury at the time of the first MESSEvGEa flyby. Karus, in press. doi:10.1016] jicarus $2009,11.036$

Berezhnoy, A.A. Khumov. B.A. 2008. Impacts as sources of the exosphere of Mercury. larus $195,511-522$

Stida, T.A. Killen, KM. Morgan, T.H. 2000, Discovery of $\mathrm{Ca}$ in the atmosphere of Mercury. Nature 404, 159-161

Born, P.. Cremonese, G, Marzari, F., Bruno, M. Marchí, S., 2009. Statistical analysis of micrometeoroids fux on Mertury. Astron. Astrophys. $503,259-264$.

Brown, M.E., 2001. Potassium in Europd's Atmosphere. lcarus 151, 190-195.

Burget, M.Y. Killen, R.M., Vervack ir., R. ., Bradley, T., McClintock, W.E., Sarantos, M. Benna, M. Movawad, N. 2010. Monte Carlo modelng of sodium in Mercury's exosphere during the first wo MESSENGER fybys, Karis, submited for publication.

Chamberlain, IW. Hunten, D.M, 1987. Theory of Planctary Atmospheres. Academic

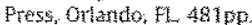

Cheng, A.E. Johnson, R.E, Krimigis; 5.M., Lanzerotti, LI, 198\%. Magnetosphere. exosphere and surface of Mercury. lcarus 77,430440

Cintala. M.E., 1992. Impact-induced themal effects in the hand and mercuran rezoliths. I. Geophys. Res. 97, 947\%,973

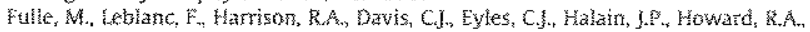
Bockelee-Morvan, D. Cremonese, G., scamato, $T, 2007$. Discovery of the atomic iron tail of Comet McNatught using the heldospheric imager on STepeo, Astrcohys. I. $664,193 \sim 196$.

Gauh; W.A. Rundte. H.W., 1960 . Twilght observations of upper atmospheric sedium, potassium, and lithium. Can. I. Phys. $47,85,98$.

Hayderer, $G$, and 11 colleagues, 2004 . Kineticalyy assisted potentiat sputtering of instuators by highly chatged ions, Phys, fev. Lett $86,3530 \mathrm{~m} 3533$

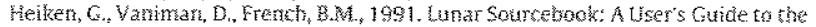
Muon. Cambridge Univ. Press. $736 \mathrm{gp}$

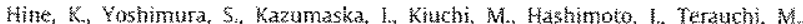
Nishtrani, M. Hamaguchi, S., 2007. Meastrement of magnesium axide sputtering yields by he and Ar lons with a low-energy mass-selected ion beam system. Jpn. J. Appl. Phys. 46, L1132-11134.

Hubner, W.F. Keadv, I.f., Lyon, S.P., 1992. Solar photo rates for planetary atmospheres and atmospheric poilutants. Astrophys Space Scl. 195, 294.

Joly, $A_{\text {. }}$ 2002. Femtosecond time-resolved photon-stimulated aesorption from ionto Crystals. Appl. Surface Sci, 1 b6, 339-344.

Kallo, E. Jantunen, P. 2003. Solar wind and magnetospheric ion impace on Mercurys strface. Geophys. Res, Lett. 30,550 2.1\%2.4. doi: 10.1020 2003 GL017842.

Kallo, E., and 70 colleagues, 2008 . On the impact of multiply charged heavy solar wind ions on the surface of Merctry, the Moon and ceres. Manet. Space Sci. 56 $1506-1516$.

Killen, R.M. 1989. Crustal diffusion of gases out of Mercury and the Moon. Geophys. Re. Lett. $16,171+17$ a

Killen, R.M. Morgan, T.H., 1993. Duffusion of Na and $\mathrm{K}$ in the uppemost regolith of Mercury. J. Geophys. Res. $98,23589-23601$.

Killen, R.M., Morgan. T.H., 1994. Erratum: Diffusion of Na and $K$ in the uppermos regolith of Mercury 1]. Geophys. Res. $98,23589-23601$ 1. I. Geophys. Res. go $1093 \%$

Killen, R.M., Sazantos, M. 2004. Source rates and ion recycling rates for Na and K in Wercury's atmosphere. Icarus 171, 1-19.

Killen, RM., Potter, A.E, Morgan, T.H. 1990. Spatial distribution of sodium vapor in the atmosphere of Mercury. Lcarus 85, 145 167.

Killen, RM., Potter, A.E, Reiff. P., Sarantos, M., Jackson, B.V., hick, P., Giles, B., 2001 Evidence for space weather at Mercury. J. Geophys Res. 106, 20509-20525.

Killen, R.M., Bida, T.A. Morgan, T.H. 2005. The calcium exasphere of Mercury. Icaras $173,300-311$.

Killen, R.M., Shemansky, D.E, Mouawad, N., 2009, Expected emission from Mercury's exospheric species, and their UV-Visible signatures. Astrophys. Suppl. 181, 351-359.

Kurucz, R,L., Furenlid, L, Bratit, I. Festerman, L, 1984. Solar Flux Atlas from 296 to $1300 \mathrm{~nm}$. National Solar Observatory Atias No. 1. Tucson, Ariz.

Lodders, K. Fegley 1., B., 1998: The Planetary Scientist's Companion, Oxford Uniw Press, New York. $371 \mathrm{pp}$.

Love, S.G., Brownlee, D.E, 1993. A direct measurement of the tertestrial mas accretion rate of cosmic dust. Seience $262,550 m 553$.

Madey, T,E, Yakshinskiy, B.V., 1997. Desofption of Na from model mineral surfaces: Relevance to origins of Na in the atmospheres of Mercury and the Moon. Bull. Am. Astron. Soc. 13.07 (abstract) 29.987.

Madey, T.E., Yakshinskiy. B.V., Ageev, V.N., Johnson, R.E, 1998. Desorption of alkal atoms and ions from oxide surfaces: Kelevance to otigins of Na and $K$ in the atmospheres of Mercun and the Moon. I. Geoplyss Res. 103, 5873-5887. toi: $10.1029 / 981600230$.

McCintock, W.E. Laniton, M.R., 2007. The Mercury Atmospheric and Surface Composition Spectrometer for the MESSENGER mission. Space Sci. Rev, 131. $481-521$

McClintock, W.E, Vervack H., R., Bradley, E.T., Killen, R.M., Mouawad, N., Sptague, A.l. Burger, M.H., Solomon, S.C. 1zenberg. N.R. 2009. MESSENGER obserwation of Mercusty's exosphere: Detection of magnesium and distributions of species. Sciance $324,510-613$.

Melosh, H. I. 1989. Impact Cratering $\cdots$ A Geologic Process. Oxford University Press $253 \mathrm{pp}$ :

Morgan, T.H., Kilen, R.M., 1998. Production mechamismis for faint but possibly detectable coronae about asteroids, Planet. Space $5 \mathrm{ci}$. 46. 843-850.

Morgan, T.H., Zook, H.A., Potter, A.E, 1988. Impact-driven supply of sodium and potassium to the atmosphere of Mercury. Karus 75. 156-170.

Mutty, N.S., Bagare, S.P. 1978. Dissociation energy of Mgo from the true potential curve. y: Phys. B: At. Mol. Phys. 11,623-526

Nyquist, LE., Wooden, ]. Bansal, B., Weismann, H., McKaj, C.. Bogard, D.D. 1979 $\mathrm{Rb}-\mathrm{Sr}$ age of the Shergoty achondrite and implications for metamorphic resetring of isothron ages. Geochim. Cosmoctim Acta 43, 1057-1074.

Potter, A.E., Morgan, T.H. 1988. Discovery of sodium and potassium vapor in the atmosphere of the moon. Science $241,675 \cdots 680$.

Potter, A.E, Morgan, T.H., 1997. Sodium and potassium atmospheres of Mercury Planet. Space Sci, 45, 95-100.

Patter, AE, Anderson, C.M., Killen, R.G. Morgan, TH, 2002, Ratio of sodium to potassium in the Mercury exosphere I. Geophys. Res 107, 5040. dor:10.102\% $2000 \mathrm{HEO} 1493$

Ratchenka, Yu. Kramida, A.E, Reader, J, and the NIST ASD Team, 2008. NiST Atomic Spectra Database (online). National Institute of Standards and Technology, Gathersburg, $\mathrm{Md}$.

Roth, f, 1983. Chemical sputtering. In: Behrisch, R. (Ed, Sputtering by particte

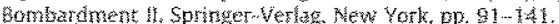

Sarantes, M., 2005. Ion Tfajectories in Mercury's Magnetosphere. Ph. D. Dissertation, Rise University Publication AAT 3176074 , Houston, 81pp:

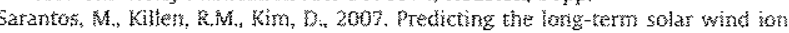
sputrering soutce at Mercury. Plantet. Space Sci. $55,1584-1395$

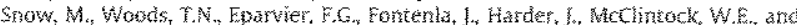

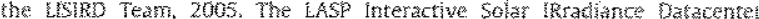

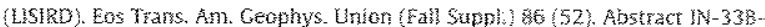
1180.

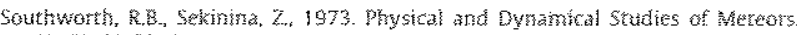
NASACE-2316. 
Sprague, A.L. Kozlowski, K.W.H., Huntef, DM., 1990. Caloris basin: An enhanced sourete for potassium in Mercury's atrnosphere. Science 249 , 1140-1143.

Wang, W.M. 2008 . 等elating the solar wind helium abundance to the coronal matanetic field. Astroplys. J. $683,499-509$.

Yakstrinskiy, BV, Madey, T,E. 1909. Photon-stimulated desorption as a substantial source of sodium in the lunar atmosphere. Nature $400,642-644$.
Yakshinskiy, B.V., Madey, T.E, 2004. Photon stimulated desorption taf Na from a iunar sample: Ternperature-dependent effects. Icwirs $168,53-50$.

Yakshinsky, B.V., Madey, T.r. 2005. Temperature-dependent DieT of alkatis from $\mathrm{SiO}_{2}$ hims: Comparison with a lunar sample. Surface Soi. 593, 202209. 